\title{
Aqueous-phase oligomerization of methyl vinyl ketone through photooxidation - Part 2: Development of the chemical mechanism and atmospheric implications
}

\author{
B. Ervens ${ }^{1,2}$, P. Renard $^{3}$, S. Tlili ${ }^{3}$, S. Ravier ${ }^{3}$, J.-L. Clément ${ }^{4}$, and A. Monod $^{3}$ \\ ${ }^{1}$ Cooperative Institute for Research in Environmental Sciences, University of Colorado, Boulder, Colorado, USA \\ ${ }^{2}$ Chemical Sciences Division, NOAA Earth System Research Laboratory, Boulder, Colorado, USA \\ ${ }^{3}$ Aix Marseille Université, CNRS, LCE FRE 3416, 13331, Marseille, France \\ ${ }^{4}$ Aix Marseille Université, CNRS, ICR UMR7273, 13397, Marseille, France
}

Correspondence to: B. Ervens (barbara.ervens@noaa.gov)

Received: 29 July 2014 - Published in Atmos. Chem. Phys. Discuss.: 22 August 2014

Revised: 20 May 2015 - Accepted: 13 June 2015 - Published: 17 August 2015

\begin{abstract}
Laboratory experiments of efficient oligomerization from methyl vinyl ketone (MVK) in the bulk aqueous phase were simulated in a box model. Kinetic data are applied (if known) or fitted to the observed MVK decay and oligomer mass increase. Upon model sensitivity studies, in which unconstrained rate constants were varied over several orders of magnitude, a set of reaction parameters was found that could reproduce laboratory data over a wide range of experimental conditions. This mechanism is the first that comprehensively describes such radical-initiated oligomer formation.

This mechanism was implemented into a multiphase box model that simulates secondary organic aerosol (SOA) formation from isoprene, as a precursor of MVK and methacrolein (MACR) in the aqueous and gas phases. While in laboratory experiments oxygen limitation might occur and lead to accelerated oligomer formation, such conditions are likely not met in the atmosphere. The comparison of predicted oligomer formation shows that MVK and MACR likely do negligibly contribute to total SOA as their solubilities are low and even reduced in aerosol water due to ionic strength effects (Setchenov coefficients). Significant contribution by oligomers to total SOA might only occur if a substantial fraction of particulate carbon acts as oligomer precursors and/or if oxygen solubility in aerosol water is strongly reduced due to salting-out effects.
\end{abstract}

\section{Introduction}

Organic aerosol particles in the atmosphere comprise about $50 \%$ of the total particulate matter mass (Zhang et al., 2007). A small fraction of them are emitted directly by various sources (primary organic aerosol, POA); the major portion is formed by chemical and/or physical processes during their residence time in the atmosphere (secondary organic aerosol, SOA) (Kanakidou et al., 2005). Traditionally, it has been assumed that SOA is formed by condensation of low-volatility or semivolatile organic products that represent gas-phase oxidation products from emitted precursor compounds. SOA formation from such products (termed "gasSOA" by Ervens et al. (2011) since the chemical reactions leading to condensable species occur in the gas phase) is often described by the two-product model (Odum et al., 1996) or, more recently, by the volatility basis set (VBS) (e.g., Donahue et al., 2006, 2011; Trump and Donahue, 2014). While this concept can explain a large amount of observed ambient SOA mass, specific SOA properties (e.g., high oxygen-to-carbon $(\mathrm{O} / \mathrm{C})$ ratio) and individual compounds (e.g., dicarboxylic acids, oligomers) cannot be predicted.

Several recent laboratory, field and model studies point to efficient chemical reactions in the aqueous phase of cloud/fog droplets and aerosol particles, which lead to lowvolatility products that remain in the particle phase upon water evaporation ("aqSOA", Ervens et al., 2011). However, the contribution of aqSOA to total ambient SOA loading has not been quantified yet due to the poor mechanistic understand- 
ing, which makes a comprehensive implementation in models difficult and ambiguous. Systematic laboratory experiments have been performed in order to elucidate the SOA formation potential of individual precursors such as small carbonyl compounds (Lim et al., 2010; Noziere et al., 2010; Ervens et al., 2011, and references therein).

Several laboratory experiments focused on SOA precursors that are formed from isoprene (Kroll et al., 2005, 2006; Altieri et al., 2006; Kuwata et al., 2015). Isoprene emission rates exceed those of all other anthropogenic and biogenic organics, and thus even a small yield $(<5 \%)$ might significantly contribute to the total SOA burden (Carlton et al., 2009). Isoprene has a low water solubility $\left(K_{\mathrm{H} \text {,isoprene }}=\right.$ $0.013 \mathrm{M} \mathrm{atm}^{-1}$, Mackay and Shiu, 1981) and, thus, its fraction in the atmospheric aqueous phases is $<0.001 \%$, related to the total atmospheric isoprene concentration. Its firstgeneration oxidation products, methyl vinyl ketone (MVK) and methacrolein $(\mathrm{MACR})$, are more soluble $\left(K_{\mathrm{H}, \mathrm{MACR}}=\right.$ $6.5 \mathrm{M} \mathrm{atm}^{-1} ; K_{\mathrm{H}, \mathrm{MVK}}=41 \mathrm{M} \mathrm{atm}^{-1}$; Iraci et al., 1999), but, yet, their aqueous-phase fraction in pure water is $<1 \%$. However, simultaneous measurements of similar small carbonyl compounds in the gas and particle phases have shown that a substantial fraction of them might be associated with the particulate phase (Baboukas et al., 2000; Matsunaga et al., 2005; Healy et al., 2008; Kampf et al., 2013; Kawamura et al., 2013) and thus accumulate in aerosol water. Solubility in non-ideal solutions has often been parameterized by the Setchenov coefficient that predicts salting-in or salting-out effects, depending on the chemical structure and concentration of the compound (Paasivirta et al., 1999; Wang et al., 2014).

Several recent laboratory studies have explored the reactivity of MVK and MACR in the aqueous phase, and depending on the initial concentration, efficient formation of oligomeric compounds has been observed (Zhang et al., 2010; Renard et al., 2013). Organics with oligomeric (or polymeric) structures have also been identified in other laboratory experiments (Kalberer et al., 2004; Tolocka et al., 2004) and ambient aerosol particles (Denkenberger et al., 2007; Polidori et al., 2008; Mazzoleni et al., 2010; Zhang and Ying, 2011) as well as in rainwater (Altieri et al., 2009; Mead et al., 2013, 2015). However, to date the explicit chemical pathways leading to oligomers are not fully implemented into atmospheric chemistry models since the chemical mechanisms are not available. The current study aims at contributing to close this gap by presenting the kinetic and mechanistic details of chemical pathways to explain the observed oligomer formation from MVK during the bulk aqueous-phase experiments that were presented by Renard et al. (2013), and in the companion paper of this study (Renard et al., 2015, referred to as "Part I" hereafter). By fitting kinetic rate constants and combining them with known constants for basic chemical processes, a comprehensive chemical mechanism for the oligomerization of MVK in the aqueous phase is derived (Sect. 2). This mechanism is used in a multiphase box model and sensitivities of the oligomerization rate to the solubility of MVK and oxygen are shown (Sect. 3). In the same section, the question is explored under what atmospheric conditions aqSOA formation by oligomerization might be of importance as an efficient SOA source. For this estimate, we include similar reaction patterns in the aqueous phase for MACR as for MVK and imply the existence of additional oligomer precursors.

\section{Experiment-model comparisons}

\subsection{Chemical mechanism development}

\subsubsection{Kinetic data for individual processes}

The analysis of the resulting oligomers was performed by ultra-high-performance liquid chromatography mass spectrometry (UPLC-ESI-MS). All analytical methods are discussed in detail in Part I. In brief, the temporal evolution of the MVK, $\mathrm{H}_{2} \mathrm{O}_{2}$ and $\mathrm{O}_{2}$ aqueous concentrations and $\mathrm{pH}$ were recorded during the laboratory experiments using liquid chromatography UV-DAD absorbance spectroscopy (UPLC$\mathrm{UV}$, for MVK and $\mathrm{H}_{2} \mathrm{O}_{2}$ concentrations). Dissolved oxygen concentrations and $\mathrm{pH}$ were measured by a multi-parameter analyzer (Consort C3020). The $\mathrm{OH}$ concentration in the aqueous phase could not be directly measured. However, it could be derived based on the observed photolytic loss of hydrogen peroxide. Experiments in the absence of MVK revealed a photolysis rate of $9.5( \pm 1.4) \times 10^{-6} \mathrm{~s}^{-1}$. This rate decreased as a function of MVK concentrations (Sect. 2.2.2). Cross-reactions of $\mathrm{OH}, \mathrm{HO}_{x}$ and $\mathrm{H}_{2} \mathrm{O}_{2}$ were included in the model to account for the recycling of these species $\left(\mathrm{HO}_{x}\right.$ reactions in Table 1). The chemical mechanism of MVK decay and oligomer formation as suggested by Renard et al. (2013) has been adapted here with some minor modifications in order to constrain kinetic data (Fig. 1). Not all intermediates were detected during the experiments; however, the structure of the resulting oligomers was used to deduce the most likely reaction pathways. As an $\alpha, \beta$-unsaturated carbonyl, MVK bears highly reactive conjugated carbon-carbon and carbon-oxygen double bonds. Therefore, its oxidation by $\mathrm{OH}$ might occur via three reaction channels: $\mathrm{OH}$ might add to the vinyl group of the MVK molecule either (1) on the $\beta$-carbon atom or (2) on the $\alpha$-carbon atom, or (3) it might abstract a hydrogen atom from either the vinyl group or from the saturated end of the molecule. Pathways (1) and (2) lead to isomeric hydroxyalkyl radicals with identical molecular weights and, thus, neither the initiator radicals nor the resulting oligomers, respectively, are distinguishable with the analytical techniques (mass spectrometry) applied here. In a thorough study of reaction products, Schöne et al. (2014) have identified oxidation products formed on both reaction pathways, but no branching ratio could be determined either. 


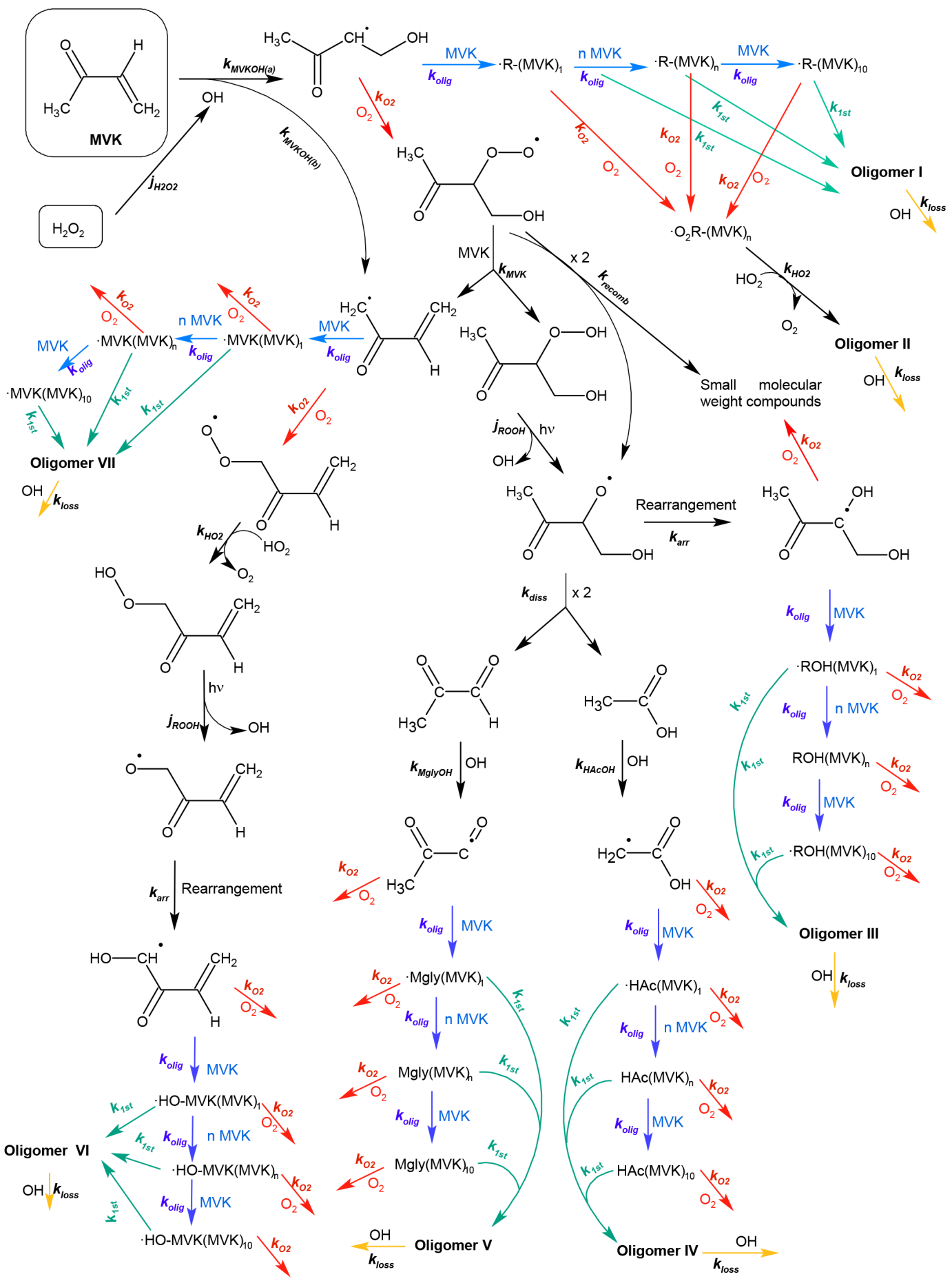

Figure 1. Chemical mechanism, constrained by laboratory studies for different conditions $[\mathrm{MVK}]_{0},\left[\mathrm{H}_{2} \mathrm{O}_{2}\right]_{0}$. Reactions that are marked by the same color are assumed to occur with identical rate constants $\left(k_{\mathrm{olig}}, k_{\mathrm{O}_{2}}, k^{1 \mathrm{st}}, k_{\text {loss }}\right.$, respectively). All rate constants are summarized in Table 1 .

Theoretically, $\mathrm{OH}$ addition on the $\beta$-carbon atom (pathway 1 ) is favored on both steric and resonance grounds; the propagating radical formed by this pathway (1) is the more stable one (Odian, 2004; Schöne et al., 2014). An at- tempt to distinguish between the three pathways was performed by direct observation and quantification of the resulting alkyl radicals using continuous-flow electron paramagnetic resonance (EPR) experiments with MVK concen- 
Table 1. Rate constants (at $298 \mathrm{~K}$ ) for the processes in Fig. 1.

\begin{tabular}{|c|c|c|c|}
\hline Symbol & Description & $k$ & Reference/comment \\
\hline$k_{\mathrm{MVKOH}(\mathrm{a})}$ & $\begin{array}{l}\text { Oxidation of MVK by } \mathrm{OH} \text { radical, } \\
\text { addition to the } \mathrm{C}=\mathrm{C} \text { bond }\end{array}$ & $7.18 \times 10^{9} \mathrm{M}^{-1} \mathrm{~s}^{-1}$ & $\begin{array}{l}\text { The total rate constant is } k_{\mathrm{MVKOH}}= \\
7.3 \times 10^{9} \mathrm{M}^{-1} \mathrm{~s}^{-1} \\
\text { Schöne et al. (2014) } \\
\text { The branching ratio }(98.4 / 1.6 \%) \text { was } \\
\text { set based on EPR studies (cf. text and } \\
\text { Sect. S1 in the Supplement) }\end{array}$ \\
\hline$k_{\mathrm{MVKOH}(\mathrm{b})}$ & $\begin{array}{l}\text { Oxidation of MVK by OH radical, } \\
\mathrm{H} \text {-abstraction from methyl group }\end{array}$ & $1.17 \times 10^{8} \mathrm{M}^{-1} \mathrm{~s}^{-1}$ & \\
\hline$k_{\mathrm{O}_{2}}$ & $\begin{array}{l}\text { Peroxy radical formation from alkyl } \\
\text { radicals }\end{array}$ & $3.1 \times 10^{9} \mathrm{M}^{-1} \mathrm{~s}^{-1}$ & $\begin{array}{l}\text { Average value of rate constant } \mathrm{R} \cdot+\mathrm{O}_{2} \\
\text { Neta et al. (1990) }\end{array}$ \\
\hline$k_{\text {olig }}^{*}$ & $\begin{array}{l}\text { Addition of } n \text {th MVK monomer } \\
(1 \leq n \leq 10)\end{array}$ & $5 \times 10^{7} \mathrm{M}^{-1} \mathrm{~s}^{-1}$ & $k=10^{2}-10^{4} \mathrm{M}^{-1} \mathrm{~s}^{-1}$ in Odian (2004) \\
\hline$k_{\text {loss }}^{*}$ & $\begin{array}{l}\text { Oxidation of oligomers by } \mathrm{OH} \\
\text { radical }\end{array}$ & $10^{8} \mathrm{M}^{-1} \mathrm{~s}^{-1}$ & $\begin{array}{l}\text { Average } k_{\mathrm{OH}} \text { for large organic } \\
\text { compounds, e.g., Arakaki et al. (2013); } \\
\text { Doussin and Monod (2013) }\end{array}$ \\
\hline$j_{\mathrm{ROOH}}$ & Photolysis of hydroxyperoxides & Same as $j_{\mathrm{H}_{2} \mathrm{O}_{2}}$ & \\
\hline$k^{1 \mathrm{st}^{*}}$ & $\begin{array}{l}\text { Simplified first-order reaction: } \\
\text { conversion of oligomer radicals } \\
\text { to stable products }\end{array}$ & $6 \times 10^{4} \mathrm{~s}^{-1}$ & $\begin{array}{l}\text { Estimated in order to reproduce } \\
\text { observed increase in oligomer mass } \\
\text { (Sect. 2.2.4) }\end{array}$ \\
\hline$k_{\text {arr }}^{*}$ & Rearrangement reaction & $8 \times 10^{6} s^{-1}$ & Gilbert et al. (1994) \\
\hline$k_{\text {recomb }}^{*}$ & Recombination of radicals & $2.4 \times 10^{6} \mathrm{~s}^{-1}$ & Estimated as $30 \%$ of $k_{\text {arr }}$ \\
\hline$k_{\text {diss }}$ & Dissociation of radicals & $10^{6} \mathrm{~s}^{-1}$ & \\
\hline$k_{\mathrm{MglyOH}}$ & $\begin{array}{l}\text { Oxidation of methylglyoxal by } \mathrm{OH} \\
\text { radical }\end{array}$ & $6.1 \times 10^{8} \mathrm{M}^{-1} \mathrm{~s}^{-1}$ & Schaefer et al. (2012) \\
\hline$k_{\mathrm{HAcOH}}$ & $\begin{array}{l}\text { Oxidation of acetic acid/acetate by } \\
\text { OH radical }\end{array}$ & $\begin{array}{l}1.5 \times 10^{7} \mathrm{M}^{-1} \mathrm{~s}^{-1}(\mathrm{HAc}) \\
10^{8} \mathrm{M}^{-1} \mathrm{~s}^{-1}\left(\mathrm{Ac}^{-}\right)\end{array}$ & Chin and Wine (1994) \\
\hline$k_{\mathrm{HO}_{2}}$ & $\begin{array}{l}\text { Recombination reaction of } \mathrm{RO}_{2} \\
\text { with } \mathrm{HO}_{2} / \mathrm{O}_{2}^{-}\end{array}$ & $\begin{array}{l}8 \times 10^{5} \mathrm{M}^{-1} \mathrm{~s}^{-1}\left(\mathrm{HO}_{2}\right) \\
9.7 \times 10^{7} \mathrm{M}^{-1} \mathrm{~s}^{-1}\left(\mathrm{O}_{2}^{-}\right)\end{array}$ & Estimated equal to $\mathrm{HO}_{2}+\mathrm{HO}_{2} / \mathrm{O}_{2}^{-}$ \\
\hline \multicolumn{4}{|c|}{$\mathrm{HO}_{x}$ reactions } \\
\hline \multicolumn{2}{|c|}{$\mathrm{H}_{2} \mathrm{O}_{2}+\mathrm{h} v \rightarrow 2 \mathrm{OH}$} & $j_{\mathrm{H}_{2} \mathrm{O}_{2}}=f\left([\mathrm{MVK}]_{0}\right)$ & $\begin{array}{l}\text { Experimentally } \\
\text { determined, cf. Fig. } 3\end{array}$ \\
\hline \multicolumn{2}{|c|}{$\mathrm{H}_{2} \mathrm{O}_{2}+\mathrm{OH} \rightarrow \mathrm{HO}_{2}+\mathrm{H}_{2} \mathrm{O}$} & $3 \times 10^{7} \mathrm{M}^{-1} \mathrm{~s}^{-1}$ & Christensen et al. (1982) \\
\hline \multicolumn{2}{|c|}{$\mathrm{HO}_{2}+\mathrm{HO}_{2} / \mathrm{O}_{2}^{-} \rightarrow \mathrm{O}_{2}+\mathrm{H}_{2} \mathrm{O}_{2}$} & $\begin{array}{l}8 \times 10^{5} \mathrm{M}^{-1} \mathrm{~s}^{-1}\left(\mathrm{HO}_{2}\right) \\
9.7 \times 10^{7} \mathrm{M}^{-1} \mathrm{~s}^{-1}\left(\mathrm{O}_{2}^{-}\right)\end{array}$ & Bielski et al. (1985) \\
\hline \multicolumn{2}{|c|}{$\mathrm{OH}+\mathrm{HO}_{2} / \mathrm{O}_{2}^{-} \rightarrow \mathrm{H}_{2} \mathrm{O}+\mathrm{O}_{2}$} & $10^{10} \mathrm{M}^{-1} \mathrm{~s}^{-1}$ & Elliot and Buxton (1992) \\
\hline
\end{tabular}

* For sensitivity studies on these constants, cf. Sect. S4.

trations from 1 to $25 \mathrm{mM}$ (Sect. S1 in the Supplement). The obtained highly complex spectra were the result of superimposition of various EPR signals. Using spectral simulations, the signal of the $\mathrm{HO}-\mathrm{CH}_{2}-{ }^{\cdot} \mathrm{CH}-\mathrm{C}(\mathrm{O}) \mathrm{CH}_{3}$ radical adduct resulting from pathway (1) was clearly distinguished (dots in Fig. S1 in the Supplement). Contributions of another transient radical were found to depend on the initial MVK concentration (compare the spectra in Fig. S1a and b). A very similar behavior of concentration dependence of radical species was previously observed in experiments performed on acrylic acid by Gilbert et al. (1994), and they attributed this behavior to the formation of dimer radicals. Therefore, the concentration-dependent radical was attributed to a dimer radical such as $\mathrm{HO}-\mathrm{CH}_{2}-\mathrm{CH}\left(\mathrm{C}(\mathrm{O}) \mathrm{CH}_{3}\right)-$
$\mathrm{CH}_{2}-{ }^{\cdot} \mathrm{CH}-\mathrm{C}(\mathrm{O}) \mathrm{CH}_{3}$, thus confirming a very fast recombination pathway (Gilbert et al., 1994). More than two different radical species were present in our experiments, but their respective signals remained unidentified due to overlapping EPR signals in the spectra. Although it was not possible to identify these other radical species, the occurrence of radicals resulting from pathways (2) and (3) was expected, and the EPR experiments showed that their relative importance was much lower than that of pathway (1). In the model, we lump pathways (1) and (2) to the more likely radical from pathway (1) that was identified by EPR ( $k_{\mathrm{MVKOH}(\mathrm{a}) \text {, }}$ Fig. 1). H-abstraction (pathway 3 ) would occur most likely on the most weakly bonded H-atoms, which are the ones in the methyl group (bond energy $\sim 94 \mathrm{kcal} \mathrm{mol}^{-1}$, as opposed 
to $\sim 111 \mathrm{kcal} \mathrm{mol}^{-1}$ for the other $\mathrm{H}$-atoms of the molecule, Blanksby and Ellison, 2003) and stabilization of the resulting radical due to the adjacent carbonyl group $\left(k_{\mathrm{MVKOH}(\mathrm{b})}\right)$ Fig. 1).

The overall rate constant for the reaction of MVK with $\mathrm{OH}$ has been recently determined as $k_{\mathrm{MVKOH}}=7.3 \times$ $10^{9} \mathrm{M}^{-1} \mathrm{~s}^{-1}$ (Schöne et al., 2014). Since the branching ratios for the various reaction pathways are not known, we assume that pathway (3) might occur with a similar rate constant as $\mathrm{H}$-abstraction from the structurally similar acetone $\left(k_{\mathrm{OH} \text {,Acetone }}=1.2 \times 10^{8} \mathrm{M}^{-1} \mathrm{~s}^{-1}\right.$, Ervens et al., 2003; Monod et al., 2005). The ratio between the overall rate constants $k_{\mathrm{OH} \text {,Acetone }} / k_{\mathrm{MVKOH}} \sim 1.6 \%$ is in qualitatively good agreement with (i) our EPR results and (ii) the calculation of the possible amounts of $\mathrm{H}$-abstraction reaction by Schöne et al. (2014) that both suggest a minor contribution of the $\mathrm{H}$-abstraction pathway.

The resulting alkyl radicals can react with dissolved oxygen to form peroxy radicals $\mathrm{RO}_{2}$. The rate constant for this step for all radicals is assumed to be nearly diffusion-controlled with $k_{\mathrm{O}_{2}}=3.1 \times 10^{9} \mathrm{M}^{-1} \mathrm{~s}^{-1}$ based on the overview by Neta et al. (1990). In previous model efforts to fit experiments of small organic compounds in aqueous solution, it was assumed that $k_{\mathrm{O}_{2}}$ could be substantially smaller $\left(k_{\mathrm{O}_{2}} \sim 10^{6} \mathrm{M}^{-1} \mathrm{~s}^{-1}\right.$ ) (Guzman et al., 2006; Lim et al., 2010; 2013). However, a literature review of rate constants for numerous similar compounds (Alfassi, 1997; Schaefer et al., 2015) reveals that all constants for such reactions are in a range of $2 \times 10^{9} \mathrm{M}^{-1} \mathrm{~s}^{-1}<k_{\mathrm{O}_{2}}<4 \times 10^{9} \mathrm{M}^{-1} \mathrm{~s}^{-1}$. Only for non-carbon-centered radicals (such as nitrogen-centered radicals), significantly smaller rate constants are observed $\left(\sim 10^{7}-10^{8} \mathrm{M}^{-1} \mathrm{~s}^{-1}\right)$, and none of them is as low as $k_{\mathrm{O}_{2}}$ $\sim 10^{6} \mathrm{M}^{-1} \mathrm{~s}^{-1}$. An explanation for this discrepancy is the continuous depletion of oxygen during the reactant consumption (Sect. 2.2.3) that leads to a decrease of the reaction rate (i.e., the product of rate constant and concentration) with time. Thus, we suggest that in the previous experimental studies, the solutions were temporarily depleted in dissolved oxygen, and the reactions occurred with rate constants similar to $k_{\mathrm{O}_{2}}$ as used in the current study. In addition to the reaction with oxygen, the alkyl radicals can react with MVK $\left(k_{\text {olig }}\right)$ by opening its double bond. This process leads to oligomer radicals that contain multiple MVK units and can recombine to form non-radical oligomer molecules (Sect. 2.1.2).

At various places in the mechanism, rearrangement, dissociation and recombination reactions of radicals are inferred ( $k_{\text {arr }}$ and $k_{\text {recomb }}$, respectively). To our knowledge, there is no available literature value for the exact same molecules as inferred in our mechanism. However, several studies suggest rates of the rearrangement reactions $\left(k_{\text {arr }}\right)$ on the order of $10^{6}-10^{7} \mathrm{~s}^{-1}$ (Gilbert et al., 1976; Schuchmann and von Sonntag, 1981, 1984). While no data are available for the ratio $k_{\text {arr }} / k_{\text {recomb }}$ for the molecules as in our mechanism, we assumed the ratio to be the same as for primary ethers (von
Sonntag and Schuchmann, 1997). Since data for the exact compounds are not available, they have been estimated based on those for structurally similar compounds (NDRL/NIST, 2002). These steps are assumed based on the carbon structure of the resulting detected oligomers. We performed sensitivity studies on the most uncertain and least constrained rate constants. Results are summarized in Sect. S4. They show that the simulation results are insensitive to the choice of $k_{\text {arr }}$ and $k_{\text {recomb }}$; even a change of \pm 5 orders of magnitude for each of the constants gives the same results as the base case (black line in Fig. S3; results of the sensitivity studies are not displayed but would be on top of the base case results) with less than $1 \%$ difference. Simultaneous changes of $k_{\mathrm{O}_{2}}, k^{1 \mathrm{st}}$ or $k_{\text {olig }}$ can reproduce similar results for selected experimental conditions; however, the most robust results for all concentration ranges and experimental conditions were obtained for the set of rate constants as summarized in Table 1. While this agreement does not necessarily prove that indeed these are the exact rate constants, they reveal important sensitivities and suggest which rate constants should warrant future laboratory experiments.

Due to the lack of detailed data on the photolysis of organic hydroperoxides, all photolysis processes of such compounds were assumed to occur with the same rate constant as $\mathrm{H}_{2} \mathrm{O}_{2}$ photolysis (Sect. 2.2.2). This assumption is supported by the similar aqueous-phase photolysis rate constants of $\mathrm{CH}_{3} \mathrm{OOH}, \mathrm{C}_{2} \mathrm{H}_{5} \mathrm{OOH}$ and $\mathrm{H}_{2} \mathrm{O}_{2}$ (Monod et al., 2000, 2007).

\subsubsection{Model treatment of oligomer series}

The evolution of the oligomer mass exhibits a three-step kinetics that is characterized by different slopes, i.e., an initial slow increase, when oligomerization is not very efficient yet, a fast increase and a later decrease (cf. Figs. 3 and 6 in Part I). The observed oligomer increase and decrease, together with the determined mass yield, were used to constrain the rate constants in the chemical mechanism for oligomer formation and loss $\left(k_{\text {olig }}, k_{\text {loss }}\right.$ in Fig. 1 , respectively). Renard et al. (2013) identified 13 oligomer series, among which 7 series differed in their initiator radical. Each oligomer series showed the typical "haystack" pattern in the mass spectrum where signals differed by $\Delta m / z=$ $70.0419 u$ (corresponding to the exact molecular mass of MVK). The addition of similar unsaturated compounds to initiator radicals usually occurs with rate constants in the range of $10^{2} \mathrm{M}^{-1} \mathrm{~s}^{-1}<k_{\text {olig }}<10^{4} \mathrm{M}^{-1} \mathrm{~s}^{-1}$ (Odian, 2004). However, even applying the upper limit of this range did not lead to sufficiently fast MVK decay and oligomer increase as compared to the observed behavior. Only a value of $k_{\text {olig }}=5 \times 10^{7} \mathrm{M}^{-1} \mathrm{~s}^{-1}$ gave a reasonable match between observed and modeled data. The reasons for this discrepancy to literature values are not clear; they might include the facts that (i) no specific kinetic data for MVK oligomerization are available, and this compound, as part of the family of $\alpha, \beta$-unsaturated carbonyls, may have a higher oligomer- 
ization kinetics than other species, as suggested by Gilbert et al. (1994) and by our EPR studies (Sect. S1) and/or (ii) not all MVK-consuming processes are included in the mechanism in Fig. 1. Such potentially missing pathways will also lead to oligomers, since the predicted oligomer total mass yield from the developed chemical mechanism is similar to the observed one. For all series, we consider the formation of oligomers with up to 10 monomer MVK molecules, in agreement with the experimental data that showed most oligomer series had a maximum degree of polymerization $(n) \leq 10$ (with an average $n=5$ ).

In the termination step of the radical reaction chain $\left(k^{1 s t}\right)$, the oligomer radicals recombine and disproportionate to form one saturated and one unsaturated product, i.e., yielding compound pairs with $\Delta m / z=2.0157 u$. In our chemical mechanism, these oligomer pairs are lumped into one species per series (Oligomers I, III-VII, Fig. 1). Only Oligomer II is explicitly represented, since it is the only one that originates from peroxy radicals, resulting in a hydroperoxide. It does not form by recombination reaction with itself but by reaction with the more abundant $\mathrm{HO}_{2}$ radical. The equivalent peroxide compounds from the other series were not detected and are, therefore, not depicted in Fig. 1. The intermediate radicals are treated explicitly in the mechanism, i.e., 70 different radicals from 7 initiator radicals for series I-VII with $n$ monomer MVK molecules $(1 \leq n \leq 10)$, whereas the resulting oligomers are lumped into one single compound per series. For simplicity, we parameterized the termination step by a process of first-order kinetics $\left(k^{1 \mathrm{st}}\right)$. In the literature, second-order rate constants of termination reactions in radical oligomerization are typically in the range of $10^{7}-10^{9} \mathrm{M}^{-1} \mathrm{~s}^{-1}$ (Long et al., 2001). Since these are secondorder rate constants, this range is not directly comparable to the fitted value of $k^{1 \mathrm{st}}=6 \times 10^{4} \mathrm{~s}^{-1}$ but implies that the total radical concentrations might be on the order of $\sim 10^{-5}$ $10^{-3} \mathrm{M}$, which might seem high even in the relatively highly concentrated solutions used here. It should be noted that depending on chain length and/or initiator radical the rate constants for the termination steps might differ. Our mechanism is somewhat simplified, since it is assumed that recombination reactions only occur between molecules of the same series. In reality, these recombination reactions can occur between all radicals. However, since the number of processes in our model would become untraceable for recombination between all 70 radicals ( $\sim 5000$ possible processes $)$, we chose to only include recombination reactions within the same series. If all possible recombination reactions were taken into account, a smaller $k^{1 \text { st }}$ and a higher radical concentration might result in the same reaction rate. In order to keep the number of reactions reasonable within the mechanism, but yet to empirically reproduce the increase in oligomer mass as observed in the experiments by Renard et al. (2015), and due to the lack of detailed theoretical or experimental data, we assumed the same $k^{1 \text { st }}$ constants for all oligomer series.
The experiments showed that the oligomers continue to react and decrease (Figs. 7, 8 and 9 in Part I). It is assumed that this loss is caused by the continuous oxidation of oligomers by $\mathrm{OH}$ or by direct photolysis to smaller, more volatile products. For simplicity, we describe this loss in the model exclusively by the $\mathrm{OH}$ radical, even though direct photolysis of carbonyl compounds might be at least as efficient as $\mathrm{OH}$ reaction as a loss process (Epstein et al., 2013; Reed-Harris et al., 2014). The fitted $\mathrm{OH}$ rate constant $\left(k_{\text {loss }}=10^{8} \mathrm{M}^{-1} \mathrm{~s}^{-1}\right)$ is on the same order of magnitude as those for other large carbonyl compounds (Doussin and Monod, 2013).

\subsection{Experiment-model comparison: $0.2 \mathrm{mM} \leq$ $[\mathrm{MVK}]_{0} \leq 20 \mathrm{mM}$}

\subsubsection{Input data to the box model}

Four laboratory experiments were carried out that differed in the initial MVK concentration $\left([\mathrm{MVK}]_{0}=0.2,2,5\right.$, and $20 \mathrm{mM}$, respectively). The ratio of initial $\mathrm{MVK}$ and $\mathrm{H}_{2} \mathrm{O}_{2}$ was constant in all experiments $\left([\mathrm{MVK}]_{0} /\left[\mathrm{H}_{2} \mathrm{O}_{2}\right]_{0}=0.05\right)$, in order to favor the reaction of $\mathrm{OH}$ with $\mathrm{MVK}$ over its reaction with $\mathrm{H}_{2} \mathrm{O}_{2}$ by more than $90 \%$. Each experiment started with $\mathrm{H}_{2} \mathrm{O}_{2}$ photolysis alone for $\sim 10 \mathrm{~min}$, and then MVK was injected in the solution. Due to the $\mathrm{H}_{2} \mathrm{O}_{2}$ photolysis and other $\mathrm{HO}_{x}$ reactions (Table 1), dissolved $\mathrm{O}_{2}$ concentrations increased during the first $10 \mathrm{~min}$, and this increase was faster with higher initial $\mathrm{H}_{2} \mathrm{O}_{2}$ concentrations. Consequently, the initial concentration of dissolved oxygen was different for the various initial $\mathrm{H}_{2} \mathrm{O}_{2}$ concentrations $\left(\left[\mathrm{O}_{2}\right]_{0}=284\right.$, 358,436 and $505 \mu \mathrm{M}$ for the four initial $\mathrm{MVK}$ and $\mathrm{H}_{2} \mathrm{O}_{2}$ concentrations, respectively). An additional experiment with $[\mathrm{MVK}]_{0}=20 \mathrm{mM}$ was performed in a nearly deoxygenated bulk aqueous phase where $\left[\mathrm{O}_{2}\right]_{0} \sim 60 \mu \mathrm{M}$. The concentration of dissolved oxygen was highly variable with time and was continuously measured over the course of the experiments. The solutions were continuously stirred during the experiments. In order to constrain the oxygen concentration in the model, the measured oxygen concentrations for all experiments were fitted and the derived numerical approximations (Sect. S2) were used as input data to the box model since mixing (stirring) effects between gas and aqueous phases cannot be reproduced within our simple model framework. The observed increase in dissolved oxygen towards the end of the experiments (Fig. S2b-e) can be explained by oxygen formation in the recombination reactions of $\mathrm{HO}_{2} / \mathrm{O}_{2}^{-}$with $\mathrm{HO}_{2}$ and $\mathrm{OH}$ radicals, once $\mathrm{MVK}$ is completely consumed $\left(\mathrm{HO}_{x}\right.$ reactions in Table 1$)$. While this reaction always occurs over the course of the experiments, towards the end of the experiments, insufficient organic compounds are available to form alkyl radicals that could efficiently consume oxygen via peroxy radical formation.

A decrease in $\mathrm{pH}$ was observed from $\mathrm{pH} \sim 6$ to $\sim 3$ for experiments with $[\mathrm{MVK}]_{0} \geq 2 \mathrm{mM}$ and to $\mathrm{pH} \sim 4$ for $[\mathrm{MVK}]_{0} \geq 0.2 \mathrm{mM}$. This evolution was approximated by lin- 
ear fits as input to the box model (Sect. S3). This decrease in $\mathrm{pH}$ is likely caused by the formation of organic acids, such as acetic and pyruvic acids (Fig. 1) and possibly other compounds with acid functionalities that are formed upon oligomer decay $\left(k_{\text {loss }}\right)$ as shown in Part I. These products are not further tracked in the mechanism.

\subsection{2 $\quad \mathrm{H}_{2} \mathrm{O}_{2}$ photolysis rates as a function of $[\mathrm{MVK}]_{0}$}

The initial decay of MVK is only determined by its reactions with the $\mathrm{OH}$ radical $\left(k_{\mathrm{MVKOH}(\mathrm{a})}\right.$ and $k_{\mathrm{MVKOH}(\mathrm{b})}$, Fig. 1 and Table 1). Once a sufficiently high concentration of organic alkyl radicals is present, when most of the dissolved $\mathrm{O}_{2}$ is consumed, efficient oligomerization starts, which leads to additional loss of MVK. This transition from MVK consumption by only $\mathrm{OH}$ to that due to oligomerization can be seen by the two different slopes, denoted by the small blue arrows in Fig. 2b, where it is most pronounced as compared to less clear features at lower $[\mathrm{MVK}]_{0}$. Since the initial MVK concentration and $k_{\mathrm{MVKOH}}$ are known, the only unknown value in determining the initial MVK loss rate is the $\mathrm{OH}$ radical concentration in the aqueous phase, which cannot be directly measured. In independent experiments, in the absence of MVK, the loss of $\mathrm{H}_{2} \mathrm{O}_{2}$ in the aqueous phase was measured $\left(j_{\mathrm{H}_{2} \mathrm{O}_{2}}\right)$. The photolysis rate was independent of the initial $\mathrm{H}_{2} \mathrm{O}_{2}$ concentration $(0.4$ and $1 \mathrm{M})$ and was determined as $j_{\mathrm{H}_{2} \mathrm{O}_{2}}=9.5( \pm 1.4) \times 10^{-6} \mathrm{~s}^{-1}$ in pure water. However, using this value to simulate the initial decay of MVK led to a significant overestimate of this reaction rate, i.e., to a too efficient consumption of MVK, with the largest bias for experiments with the highest $[\mathrm{MVK}]_{0}$. This finding suggests that the amount of MVK in the solution affects the $\mathrm{H}_{2} \mathrm{O}_{2}$ photolysis rate due to its light absorbance around $300 \mathrm{~nm}$. Control experiments showed that MVK loss by direct photolysis was negligible compared to oxidation by $\mathrm{OH}$ under our experimental conditions (Renard et al., 2013).

Measured light intensities were used to calculate the photolysis rate at each MVK concentration according to

$j_{\mathrm{H}_{2} \mathrm{O}_{2}}=\int I_{0, \lambda} \times \varepsilon_{\lambda} \times \phi_{\lambda} \times \mathrm{d} \lambda$,

where $\varepsilon_{\lambda}$ is $\mathrm{H}_{2} \mathrm{O}_{2}$ extinction coefficient $\left(\mathrm{cm}^{3}\right.$ molecule $\left.{ }^{-1} \mathrm{~cm}^{-1}\right)$ : it was determined experimentally at the nanometer resolution up to $350 \mathrm{~nm}$, in agreement with previous work (e.g., Kwon and Kwon, 2010); $\varphi_{\lambda}$ is the $\mathrm{H}_{2} \mathrm{O}_{2}$ quantum yield for $\mathrm{OH}$ production (Herrmann et al., 2010). $\mathrm{I}_{0 \lambda}$ is the spectral irradiance (photons $\mathrm{cm}^{-2} \mathrm{~s}^{-1} \mathrm{~nm}^{-1}$ ), measured every $1.4 \mathrm{~nm}$ (up to $1039 \mathrm{~nm}$ ) using a laboratory spectroradiometer (modified SR-500 from Spectral Evolution). The resulting photodissociation coefficient $j_{\mathrm{H}_{2} \mathrm{O}_{2}}=5.1( \pm 2.0) \times 10^{-6} \mathrm{~s}^{-1}$ obtained by this actinometry calculation is comparable to the experimentally derived value $9.5( \pm 1.4) \times 10^{-6} \mathrm{~s}^{-1}$. The slightly lower value obtained by the actinometry calculation may be due to multiple light reflections in the vessel that have not been taken into
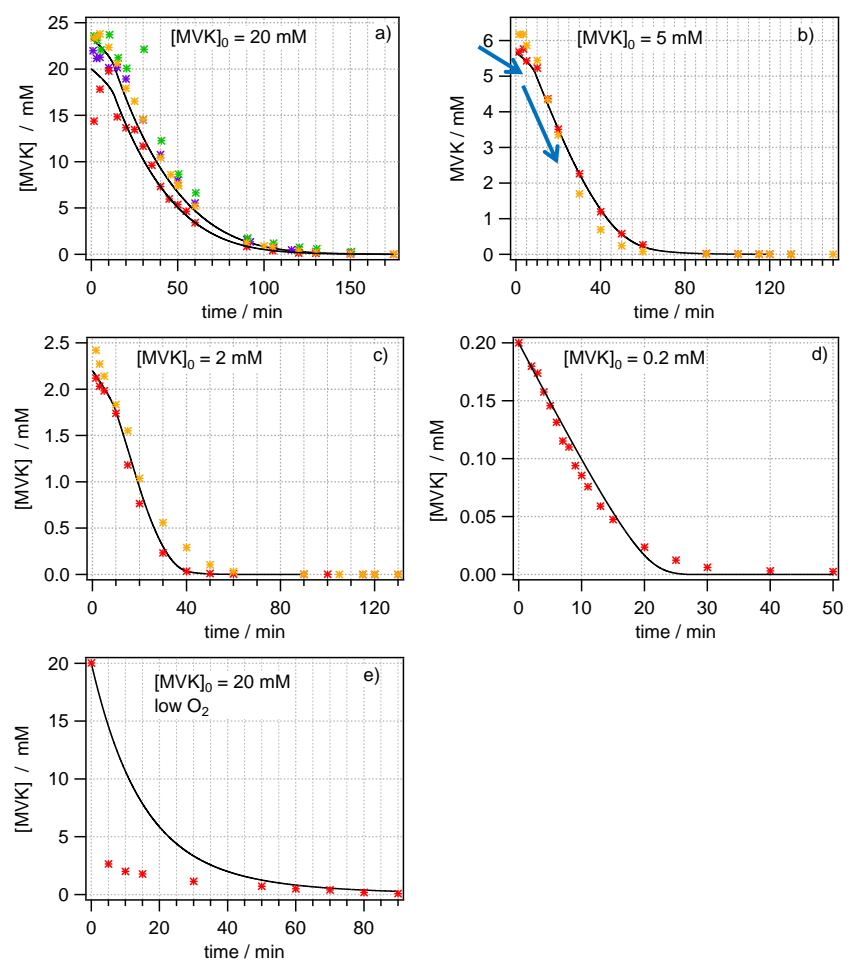

Figure 2. Comparison of experimental (symbols) and model (lines) results using the mechanism listed in Table 1 and $j_{\mathrm{H}_{2} \mathrm{O}_{2}}$ in Fig. 3 for four initial MVK concentrations (a) $\sim 20 \mathrm{mM}$ (fit to red and orange symbols); (b) $\sim 5 \mathrm{mM}$; (c) $\sim 2 \mathrm{mM}$; (d) $\sim 0.2 \mathrm{mM}$. (e) $[\mathrm{MVK}]_{0}=$ $20 \mathrm{mM}$; low oxygen concentration. Symbols of different colors denote replicate experiments.

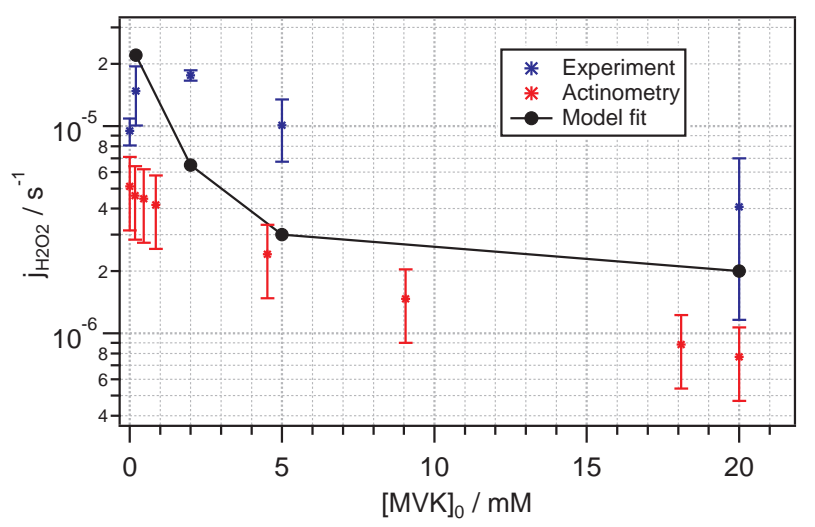

Figure 3. Experimentally determined photolysis rates for $\mathrm{H}_{2} \mathrm{O}_{2}$ (blue), and calculated data based on actinometry (red) using Eqs. (1) and (3), as a function of MVK initial concentration. Photolysis rate constants, fitted by the model in order to match MVK decay profiles for experiments with different initial MVK concentrations, are shown in black.

account in the calculation. However, this comparison is done for the direct photolysis of $\mathrm{H}_{2} \mathrm{O}_{2}$ alone in pure water.

As $j_{\mathrm{H}_{2} \mathrm{O}_{2}}$ is proportional to the incident light intensity, it is likely that its values were sensitive to the amount of absorbed 
light by MVK, depending on its concentration, and increasing with the depth of the reactor. Knowing the absorbance spectrum of MVK $\left(A_{\mathrm{MVK}, \lambda}\right)$, experimentally determined in a $1 \mathrm{~cm}$ path length cell for each concentration, and knowing the total depth of the reactor $(l=6.5 \mathrm{~cm})$, one can calculate the depth-averaged photon flux at each wavelength $\left(\bar{I}_{\lambda}^{\prime}\right)$ theoretically available for $\mathrm{H}_{2} \mathrm{O}_{2}$ photolysis (Eq. 2).

$\overline{I_{\lambda}^{\prime}}=I_{0, \lambda} \cdot \frac{1-10^{-l \cdot A_{\mathrm{MVK}, \lambda}}}{l \cdot A_{\mathrm{MVK}, \lambda} \cdot \ln 10}$.

Using this new irradiance spectrum, one can calculate the corresponding photodissociation coefficient $j_{\mathrm{H}_{2} \mathrm{O}_{2}}^{\prime}\left(\mathrm{s}^{-1}\right)$ :

$j_{\mathrm{H}_{2} \mathrm{O}_{2}}^{\prime}=\int \overline{I_{\lambda}^{\prime}} \cdot \varepsilon_{\lambda} \cdot \phi_{\lambda} \cdot \mathrm{d} \lambda$

Using the experimentally determined values of $A_{\mathrm{MVK}, \lambda}$ at different MVK concentrations, the resulting values of the photodissociation coefficient of $\mathrm{H}_{2} \mathrm{O}_{2}$ are compared to the experimental values (Fig. 3), where the kinetics of $\mathrm{H}_{2} \mathrm{O}_{2}$ decomposition have been monitored during MVK decay initiated at different MVK concentrations. The results show the same decreasing trend of $j_{\mathrm{H}_{2} \mathrm{O}_{2}}^{\prime}$ with increasing MVK concentrations for both experimentally and actinometry-derived data. In addition to these theoretical and experimental data, Fig. 3 includes photolysis rates as used in the model calculations that were adjusted to match the initial MVK loss in the experiments. This loss is solely ascribed to the reaction of MVK with $\mathrm{OH}$, and the only fitting parameter in this reaction rate is the $\mathrm{OH}$ concentration that depends directly on $j_{\mathrm{H}_{2} \mathrm{O}_{2}}$. It should be noted that the actinometry-derived data are based on the assumption of a constant (initial) MVK concentration while the model and experimental data take into account decreasing MVK concentrations. One would expect the model to agree with the experimental data rather than with the actinometry ones, which is the case for low and high initial concentrations of MVK, but it is not clear why the model better matches actinometry data at intermediate MVK concentrations.

\subsubsection{Predicted MVK decay}

Comparison of the MVK decay to the evolution of dissolved oxygen (Figs. 2 and S2) shows that MVK consumption accelerates when oxygen is (mostly) consumed. Under such conditions, the reactions of organic radicals with oxygen $\left(k_{\mathrm{O}_{2}}\right.$ in Fig. 1) become negligible, and oligomerization under nearly anaerobic conditions takes place. At low $[\mathrm{MVK}]_{0}(0.2 \mathrm{mM})$, the MVK consumption occurs over much shorter time scales than at higher initial concentrations, and the competition between $\mathrm{OH}$ reaction and oligomerization is not clearly seen. Figure 2e shows MVK decay for $[\mathrm{MVK}]_{0}=20 \mathrm{mM}$ under initially low $\mathrm{O}_{2}$ conditions, for which the reaction solution was saturated with argon. In comparison to Fig. 2a, it is obvious that the initial slow MVK decay is missing, and
MVK is quickly consumed as of the beginning of the experiment. Note the different timescales in the figures that clearly show that the reaction is completed within about half of the time at low oxygen concentrations. This sensitivity to oxygen concentrations is in agreement with the generally faster oligomerization rate under low-oxygen conditions that is well known from polymer chemistry (Odian, 2004; Mendez et al., 2013). While the reaction cell represents an aqueous volume with a very small surface-volume ratio, it will be explored in Sect. 3.2.2 whether such oxygen limitation occurs in atmospheric multiphase systems.

In theory, it might be possible that MVK and its oxidation products are also consumed by reaction with $\mathrm{H}_{2} \mathrm{O}_{2}$. In order to estimate this loss, control experiments were conducted to check for any reactivity of $\mathrm{H}_{2} \mathrm{O}_{2}$ towards MVK. MVK $(20 \mathrm{mM})$ and $\mathrm{H}_{2} \mathrm{O}_{2}(400 \mathrm{mM})$ were mixed for $300 \mathrm{~min}$ in the dark. No significant consumption of MVK or formation of oligomers was detected. Among the intermediate reaction products formed, the only reactive species towards $\mathrm{H}_{2} \mathrm{O}_{2}$ are pyruvic acid, glycolaldehyde and glyoxal $(2-4,11$ and $4 \%$ molar yield, respectively, from MVK in the aqueous phase, Zhang et al., 2010; Schöne et al., 2014). Under our experimental conditions, the rate constants of these species with $\mathrm{H}_{2} \mathrm{O}_{2}$ (Schöne and Herrmann, 2014) suggest lifetimes of $\tau$ $\sim 22 \mathrm{~s}$ for pyruvic acid, $\tau \sim 62 \mathrm{~s}$ for glycolaldehyde and $\tau$ $>4 \mathrm{~h}$ for glyoxal. While the latter is greater than our experimental timescales, the two former ones are certainly occurring in the vessel during our experiments. The reaction of pyruvic acid with $\mathrm{H}_{2} \mathrm{O}_{2}$ leads to the production of acetic acid with molar yield (Stefan and Bolton, 1999; Schöne et al., 2014). Because acetic acid is one of the identified oligomer contributors (Oligomer series IV), the reaction of pyruvic acid with $\mathrm{H}_{2} \mathrm{O}_{2}$ might, thus, artificially increase the amount of oligomers formed. Taking into account the molar yields of acetic acid $(57 \%)$ and pyruvic acid (2-4\%) (Zhang et al. 2010; Schöne et al 2014), one can conclude that this increase in oligomers is negligible. The reaction of glycolaldehyde with $\mathrm{H}_{2} \mathrm{O}_{2}$ leads to the production of formic acid with molar yield (Schöne and Herrmann, 2014; Stefan and Bolton, 1999). However, formic acid was not identified as a precursor of oligomers in our experiments; therefore, the reaction of glycolaldehyde with $\mathrm{H}_{2} \mathrm{O}_{2}$ is not assumed to influence the amount of SOA detected.

\subsubsection{Predicted oligomer formation and decay}

Figure 4 shows a qualitative comparison of predicted and observed temporal evolution of the total oligomers for the five cases depicted in Fig. 2. The observed total oligomer mass and yield were determined by means of scanning mobility particle sizer (SMPS) measurements of the nebulized solutions (cf. Part I). In the model, the oligomer mass represents a net yield, since it is the steady-state concentration from simultaneous oligomer formation $\left(k^{1 s t}\right)$ and loss $\left(k_{\text {loss }}\right)$ (Fig. 1). Despite different units, we compare the tem- 

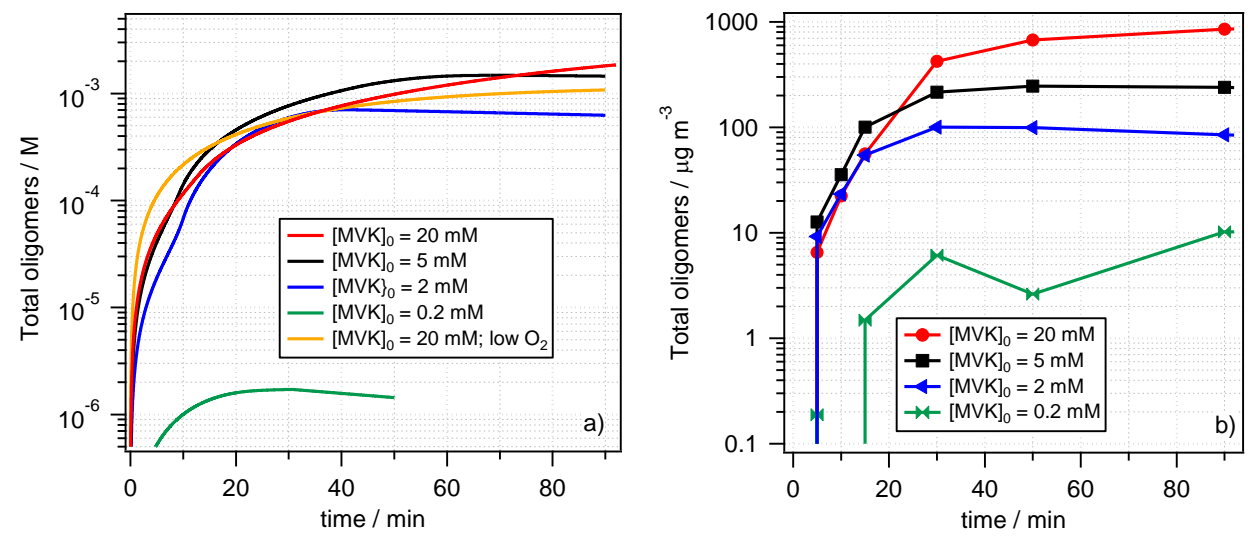

Figure 4. (a) Predicted oligomer concentrations (sum of all seven oligomer series in Fig. 1) for different initial MVK concentrations (constant $[\mathrm{MVK}]_{0} /\left[\mathrm{H}_{2} \mathrm{O}_{2}\right]_{0}$ ). (b) Total oligomer mass, determined by SMPS measurements from the nebulized solutions (cf. Fig. 7 by Renard et al., 2015, Part I).

poral evolution and the relative differences for the predicted oligomer concentrations for the four initial concentrations (and low oxygen for $[\mathrm{MVK}]_{0}=20 \mathrm{mM}$ ) (Fig. 4a). Assuming an average molecular weight for all oligomers (mass of initiator radical $+n$. MVK units $\left(n=5\right.$ for $[\mathrm{MVK}]_{0}=20 \mathrm{mM}$, and lower for lower initial concentrations)), the two units can be linearly converted for each condition; however, for model purposes, we show all model results in $\mathrm{M}$. The predicted differences of oligomer concentrations between $[\mathrm{MVK}]_{0}=$ $20 \mathrm{mM}$ and $[\mathrm{MVK}]_{0}=2 \mathrm{mM}$ are $1-2$ orders of magnitude, in agreement with the experiments. At even lower $[\mathrm{MVK}]_{0}=$ $0.2 \mathrm{mM}$, oligomer formation becomes very inefficient. Reasons for this non-linearity between initial MVK concentrations and oligomer mass might include the formation of small, volatile compounds, such as (di)acids, that are not explicitly treated by the model. Both experimental and model data show that at the highest $[\mathrm{MVK}]_{0}$, oligomer mass keeps increasing beyond the experimental time scale $(t=90 \mathrm{~min})$, whereas it is decaying for the lower $[\mathrm{MVK}]_{0}$. This behavior is in agreement with the results shown in Fig. 2, where it is shown that for the lower initial concentrations, MVK is essentially consumed at that time, and no further oligomers can be formed and the loss reaction dominates. While it has been discussed in Part I that oligomer formation is characterized by an initially slow mass increase, followed by a fast increase and then a decrease, the first step is somewhat obscured in Fig. 4 due to the logarithmic scale. Model results for $[\mathrm{MVK}]_{0}=20 \mathrm{mM}$ for high and low dissolved oxygen, respectively, show initially a much higher oligomerization rate for the latter case, in agreement with the more efficient and faster MVK decay in Fig. 2e as compared to Fig. 2a. Comparison of the oligomer increase to experimental data for the "low-oxygen case" is not performed, since it was not recorded during the experiments.

The predicted evolution of individual oligomer series is shown in Fig. 5 for $[\mathrm{MVK}]_{0}=20 \mathrm{mM}$ under conditions of high and low initial oxygen concentration. At high initial oxygen concentration, Oligomer II (Fig. 1) is the main contributor to the total oligomer concentration. This oligomer series is the only one that is directly formed from a peroxy radical whereas all others are formed from alkyl radicals and thus are suppressed when dissolved oxygen is available. As expected, under low-oxygen conditions, the concentration of Oligomer II is (much) smaller and Oligomer I has the highest concentration. Despite the lower oxygen concentration, the resulting concentration of Oligomer II is decreased by about an order of magnitude, but it still has the second highest concentration, followed by Oligomers III and VII. These oligomers need the fewest reaction steps and, thus, form most efficiently as opposed to those at the bottom of Fig. 1 (Oligomers IV, V, and VI). UPLC-ESI mass spectra of the product distribution upon MVK oxidation and oligomerization showed that the maximum concentration of the individual series occurred at $\sim 90 \mathrm{~min}$ of photooxidation. At that reaction time, assuming the oligomer relative concentrations were proportional to the relative mass spectra peak intensities, the concentrations of all detected oligomer series were in a range of 2 orders of magnitude (Renard et al., 2013); in the mass spectra data treatment, any series that contributed $<1 \%$ to the most intense peak was ignored. This result is not quite in agreement with the model results shown in Fig. 5, where the spread between the different oligomer concentrations spans about 4 orders of magnitude. This discrepancy might be due to our simplified assumptions that all oligomerization steps occur with the same rate constant, independently of their initiator radical and of their chain length. Odian (2004) showed that (i) oligomerization slows down with increasing degree of polymerization $(n)$ and (ii) the initial oligomerization rates for small $n$ might be different for different initiator radicals. Due to the lack of any detailed information on these explicit steps and trends for the individual oligomer series in our mechanism, we did not perform 

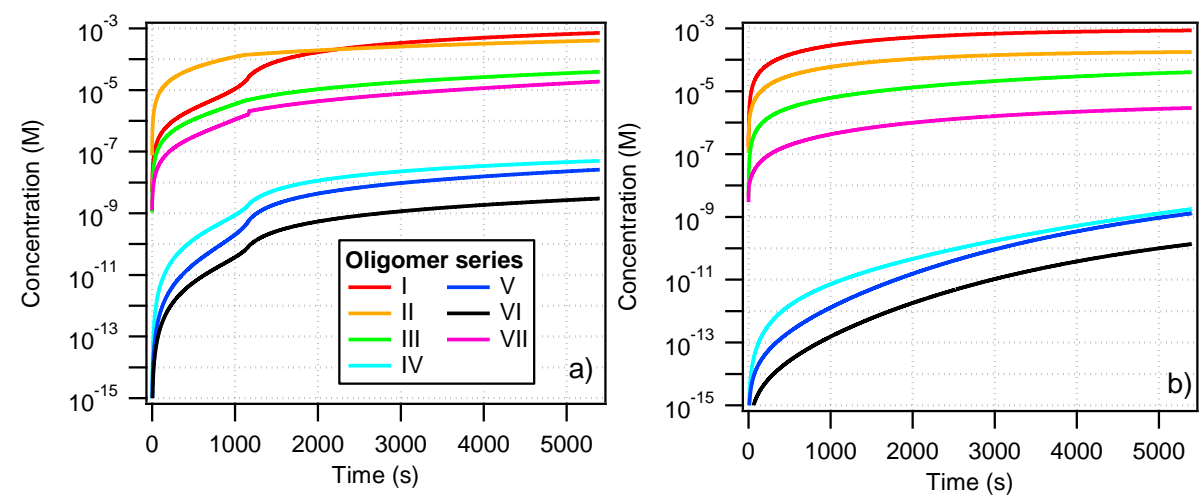

Figure 5. Comparison of predicted evolution for individual oligomer series I-VII (Fig. 1) for $[\mathrm{MVK}]_{0}=20 \mathrm{mM}$ for (a) high (saturated) and (b) low initial oxygen concentrations.

any further sensitivity studies on the rate constants. Instead in the following section, we limit our discussion to the prediction of total oligomers, i.e., the sum of Oligomers I-VII since the total predicted mass yield $(50 \leq Y \leq 100 \%)$, depending on assumed molecular weight of the oligomers is in reasonable agreement with experiments. The maximum mass yield in the experiments was $59 \%\left([\mathrm{MVK}]_{0}=20 \mathrm{mM}\right)(\mathrm{see}$ Part I) and therefore differs by less than a factor of 2 from that as predicted by the model. Note that for the estimate of the mass yield as predicted by the model, we assumed a constant molecular weight based on oligomers of five monomer units. While this estimate seems to be a reasonable average as the abundance of larger oligomers decreased with chain length, the variation of the chain length over time leads to changes in molecular weight and therefore in mass yield.

\section{Multiphase simulations}

\subsection{Phase partitioning of organics into aerosol water}

\subsubsection{Setchenov coefficients}

Henry's law constants are defined for the partitioning of species between the gas and pure aqueous phases. Several model and observational studies have shown that for many inorganic and organic compounds Henry's law constants can be used to describe the partitioning into cloud and fog water, resulting in reasonable agreement with measurements (Ervens, 2015). However, due to much higher salt concentrations in aerosol water, this aqueous medium does not comprise an ideal solution and therefore Henry's law constants should not be applied. The Setchenov coefficient $K_{\mathrm{s}}$ $\left[\mathrm{kg} \mathrm{mol}^{-1}\right]$ represents a proportionality factor for the ratio of solubilities in salt solutions $\left(K_{\mathrm{H}}^{*}\right)$ and in pure water $\left(K_{\mathrm{H}}\right)$ (Wang et al., 2014; Sander, 2015). This ratio depends on the molality of the salt solution $\left[\mathrm{mol} \mathrm{kg}^{-1}\right]$.

$\log \left(\frac{K_{\mathrm{H}}^{*}}{K_{\mathrm{H}}}\right)=-K_{\mathrm{s}}[\mathrm{salt}]$
Positive $K_{\mathrm{S}}$ values point to a salting-out effect, i.e., to reduced solubility in salt solutions as compared to pure water, whereas negative values denote a salting-in effect. The comprehensive study by Wang et al. (2014) shows that Setchenov coefficients for ketones in ammonium sulfate solutions are in the range of $\sim 0.4<K_{\mathrm{S}}\left[\mathrm{kg} \mathrm{mol}^{-1}\right]<0.6$ and in $\mathrm{NaCl}$ solutions $0.18<K_{\mathrm{S}}\left[\mathrm{kg} \mathrm{mol}^{-1}\right]<0.33$, and therefore ketones undergo a salting-out effect in these solutions. Opposite trends were found for glyoxal $\left(K_{\mathrm{S}}=-0.24( \pm 0.02) \mathrm{kg} \mathrm{mol}^{-1}\right)$ in ammonium sulfate solutions (Kampf et al., 2013). To the best of our knowledge, measurements of the Setchenov coefficient for methyl vinyl ketone or methacrolein (MACR) in salt solutions are not available. Therefore in the following, we apply a ratio of $K_{\mathrm{H}}^{*} / K_{\mathrm{H}}=0.01$, which seems applicable for a saturated ammonium sulfate solution and a Setchenov coefficient of $K_{\mathrm{S}} \sim 0.5 \mathrm{~kg} \mathrm{~mol}^{-1}$ (Fig. 6). In general, the Setchenov coefficients depend on the nature of the dissolved salt (e.g., univalent, bivalent) and other parameters such as temperature. In the case of oxygen, it has been shown that both organic (Lang, 1996) and inorganic (Battino et al., 1983) salts have a similar impact on oxygen solubility and both lead to a weak salting-out effect.

\subsubsection{Solubility and abundance of oligomer precursors}

Figure 6 suggests that the solubility of ketones might be reduced by a factor of $\sim 100$ in saturated ammonium sulfate solutions as are encountered at relative humidities $\sim 80 \%$. The resulting value $K_{\mathrm{H}, \mathrm{MVK}}^{*}=0.41 \mathrm{M} \mathrm{atm}^{-1}$, using the value determined in pure water $K_{\mathrm{H}, \mathrm{MVK}}=41 \mathrm{M} \mathrm{atm}^{-1}$ (Iraci et al., 1999), is much smaller and shows the opposite trend to the value as determined in concentrated sulfuric acid solutions $(80 \%)\left(K_{\mathrm{H}, \mathrm{MVK}}^{*}=3000 \mathrm{M} \mathrm{atm}^{-1}\right.$, Noziere et al., 2006). On the other hand, MVK and its oligomers might accumulate near the air-water interface of aerosols as observed for other compounds (Donaldson and Valsaraj, 2010), which would lead to a MVK concentration in the condensed phase in excess to that predicted based on $K_{\mathrm{H}}$. Such separation from the 


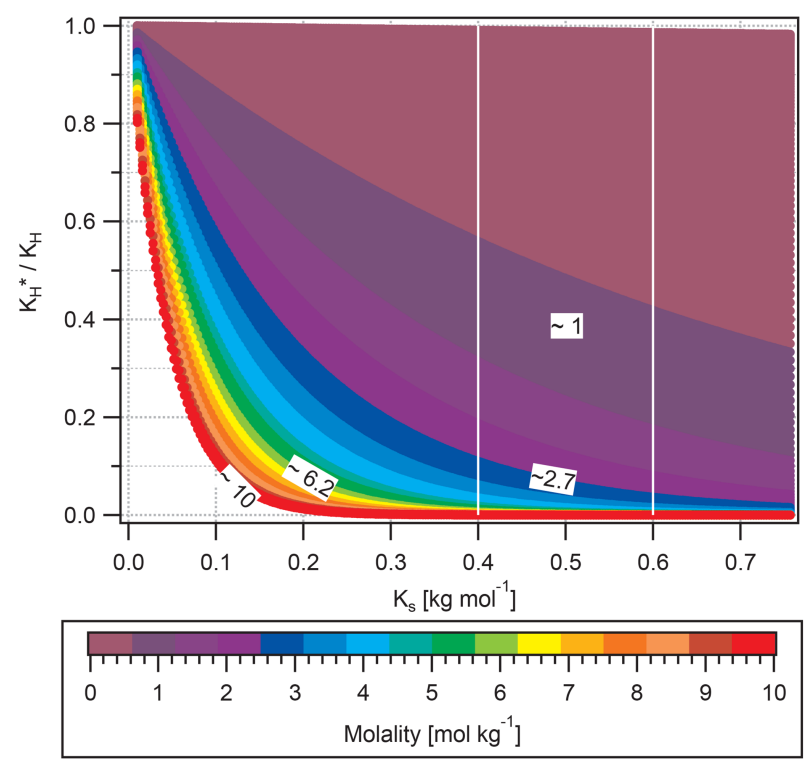

Figure 6. Reduction of solubility due to ionic strength $\left(K_{\mathrm{H}}^{*} / K_{\mathrm{H}}\right)$ as a function of Setchenov coefficient $K_{\mathrm{S}}$ according to Eq. (4). The white vertical lines show the approximate range of $K_{\mathrm{S}}$ values for ketones (Wang et al., 2014). Molalities of $\sim 2.7 \mathrm{~mol} \mathrm{~kg}^{-1}$ and $\sim 6.2 \mathrm{~mol} \mathrm{~kg}^{-1}$ (white boxes) refer to saturated ammonium sulfate and sodium chloride solutions, respectively.

bulk aqueous phase would favor heterogeneous reactions occurring at the interface, where organic concentrations are enhanced as compared to the bulk, and for which Henry's law is not applicable.

MVK can be considered a proxy compound for other unsaturated organics that might undergo similar reactions. Therefore, the concentration of potential oligomer precursors is likely greater in aerosol water than the dissolved fraction of a single compound might suggest. Lim et al. (2010) stated that millimolar aqueous concentrations $\left(c_{\mathrm{aq}}\right)$ can be considered a reasonable level of aqSOA precursors in aerosol water. This concentration corresponds to a mass concentration of a few $\mathrm{ng} \mathrm{m}^{-3}$ :

$$
\begin{aligned}
& \operatorname{LWC}(\left.\frac{20 \cdot 10^{-6} \mathrm{~g}_{\mathrm{H}_{2} \mathrm{O}}}{\mathrm{m}_{\mathrm{g}}^{3}}\right) \cdot c_{\mathrm{aq}}\left(\frac{10^{-3} \mathrm{~mol}_{\text {org }}}{\mathrm{L}_{\mathrm{H}_{2} \mathrm{O}}}\right) \\
& \cdot M_{\mathrm{org}}\left(\frac{150 \mathrm{~g}_{\mathrm{org}}}{\mathrm{mol}_{\mathrm{org}}}\right) \cdot \frac{\mathrm{L}_{\mathrm{H}_{2} \mathrm{O}}}{1000 \mathrm{~g}_{\mathrm{H}_{2} \mathrm{O}}}=3 \mathrm{ng} \mathrm{m}^{-3}
\end{aligned}
$$

for an aerosol liquid water content (LWC) of $20 \mu \mathrm{g} \mathrm{m}^{-3}$, an average molecular weight of $M_{\mathrm{org}}=150 \mathrm{~g} \mathrm{~mol}^{-1}$ for organics and a water density of $1 \mathrm{~kg} \mathrm{~L}^{-1}$. Ambient mass concentrations of several tens, up to hundreds of $\mathrm{ng} \mathrm{m}^{-3}$ were determined for small carbonyl compounds in the particulate phase (Kawamura et al., 2013). The comparison of these ranges to the estimate in Eq. (5) shows that (i) the concentration of organics in aerosol water might be much higher than millimolar, and/or (ii) only a small fraction of particu- late organics is required to initiate significant oligomer formation as observed in the laboratory experiments. Therefore, we explore in the following model studies the efficiency of oligomerization using $K_{\mathrm{H}, \mathrm{MVK}}^{*}$ and cases where the aqueous-phase concentration of unsaturated compounds, with MVK being a proxy, is on the order of $\sim 10^{-3}-1 \mathrm{M}$ as a hypothetical limit of the total of potential oligomer precursors. The total concentration of unsaturated water-soluble organic compounds in the atmosphere is not known. Several biogenic compounds, in addition to isoprene, are known to form such species upon oxidation. The molecular structure of such species might not be fully characterized and their atmospheric abundance not quantified. However, it seems unlikely that they are sufficiently abundant in the gas phase to lead to molar concentrations in aerosol water, even if their $K_{\mathrm{H}}^{*}$ values exceed those known for other SOA precursors (e.g., $K_{\mathrm{H}}^{*}$ $\sim 10^{5} \mathrm{M} \mathrm{atm}^{-1}$ ). Therefore, we conclude that this scenario might be only feasible if unsaturated water-soluble organic compounds are present in particles due to condensation and dissolve into aerosol water upon water uptake.

One other oligomer precursor is MACR, which is the other main first-generation oxidation product from isoprene. MVK and MACR are formed with gas-phase yields of 29 and $21 \%$ (with some variations, depending on $\mathrm{NO}_{x}$ levels), respectively (Galloway et al., 2011). Bulk aqueous-phase experiments have shown that also MACR efficiently forms oligomers in the aqueous phase (El Haddad et al., 2009; Liu et al., 2009; Michaud et al., 2009), but mechanistic information as detailed as for MVK is not available. MACR is less soluble than MVK $\left(K_{\mathrm{H}, \mathrm{MACR}}=6.5 \mathrm{M} \mathrm{atm}^{-1}\right.$, Iraci et al., 1999), but it has a slightly higher rate constant with $\mathrm{OH}$ in the aqueous phase, $k_{\mathrm{MACROH}}=9.4 \times 10^{9} \mathrm{M}^{-1} \mathrm{~s}^{-1}$ (Schöne et al., 2014). The mass yields of oligomers from MACR are similar to those as observed for MVK; however, the diversity of detected oligomer series is higher (Liu et al., 2012). Instead of developing an explicit chemical mechanism for MACR, in the following, we estimate its potential SOA formation efficiency scaled by that of MVK, given that both its $\mathrm{OH}$ reactivity and its overall oligomerization potential are known.

While the initial MACR decay might be somewhat faster than that for MVK, we assume that the kinetics of the subsequent MACR decay due to oligomerization and oligomer formation is comparable to that of MVK. Overall, the oligomer formation might then be approximated by a single reaction:

$\mathrm{MVK}$ or $\mathrm{MACR}+\mathrm{OH} \rightarrow$ oligomers.

In order to estimate the rate constant for Reaction (R1), $k_{\mathrm{R} 1}$, we seek a rate constant that represents best the oligomer formation as predicted by the explicit mechanism in Fig. 1. In Fig. S4, the black line shows simulations for several cases that include the full mechanism of MVK oxidation and oligomerization (Fig. 1). The dashed lines show model results, for which the reactions involving MVK (i.e., initial $\mathrm{OH}$ reaction and the subsequent oligomerization steps) 
were replaced by Reaction (R1) with different $k_{\mathrm{R} 1}$ values. While it is obvious that such a single reaction step cannot fully reproduce the wide range of oligomerization rates as predicted by the explicit mechanism, $k_{R 1}$ can be bounded by $1 \times 10^{9} \mathrm{M}^{-1} \mathrm{~s}^{-1}<k_{\mathrm{R} 1}<1.5 \times 10^{9} \mathrm{M}^{-1} \mathrm{~s}^{-1}$ as it reproduces for most cases both the temporal evolution and the final oligomer mass reasonably well (Table S3 in the Supplement). In the following model studies, we use therefore an average value of $k_{\mathrm{R} 1}=1.5 \times 10^{9} \mathrm{M}^{-1} \mathrm{~s}^{-1}$ in order to describe the $\mathrm{OH}$-initiated oligomerization from MACR, whereas we apply the full mechanism (Fig. 1 and Table 1) for MVK. We do not suggest that oligomerization by any of these compounds should be indeed represented by Reaction (R1) in future model studies, since both the temporal evolution and the kinetics might be different for other conditions $\left(N_{\mathrm{a}}, \mathrm{LWC}\right.$, $\left[\mathrm{OH}_{(\mathrm{aq})}\right]$ etc.). The only purpose of $k_{\mathrm{R} 1}$ is to develop a shortcut that allows us to estimate the role of oligomerization from MACR in our model and to roughly estimate and compare its aqSOA formation potential.

\subsection{Description of the box model and initial conditions}

In order to assess the importance of oligomerization as an aqSOA source under atmospheric conditions, we apply the same box model as in Sect. 2. However, instead of initializing aqSOA precursors, $\mathrm{O}_{2}$ and $\mathrm{H}_{2} \mathrm{O}_{2}$ in the aqueous phase, gasphase species are initialized, and their uptake into the aqueous phase of aerosol particles is described by the resistance model (Schwartz, 1986). Initial gas-phase mixing ratios and uptake parameters are summarized in Table 2. In the atmospheric multiphase system, MVK is also oxidized in the gas phase by $\mathrm{OH}$; other sinks that are likely less important (direct photolysis, reaction with $\mathrm{O}_{3}$ ) are not considered here. It is assumed that both $\mathrm{H}_{2} \mathrm{O}_{2}$ and $\mathrm{O}_{2}$ have constant gas-phase mixing ratios over the course of the simulations (1 ppb and $0.21 \mathrm{~atm}$, respectively). It is assumed that all organic products (oligomers and smaller oxidation products, Fig. 1) remain in the aqueous phase. This simplification might bias the predicted oligomer formation rates since small products such as acetic or pyruvic acids might evaporate due to their high vapor pressure. However, in the atmosphere, these compounds might be produced by other processes in the gas phase and be taken up into the aqueous phase and initiate oligomer formation via the processes described here. Since our model studies are considered being very exploratory at this point, we assume that our assumption of no evaporation might affect the predicted oligomer masses only to a minor extent.

The aqueous phase is composed of aqueous particles with a diameter of $D_{\text {wet }}=200 \mathrm{~nm}$ and a concentration $N_{\mathrm{a}}=$ $5000 \mathrm{~cm}^{-3}$, which gives a total liquid water content of LWC $\sim 20 \mu \mathrm{g} \mathrm{m}^{-3}$, being typical for deliquesced aerosol particle loadings in the atmosphere.

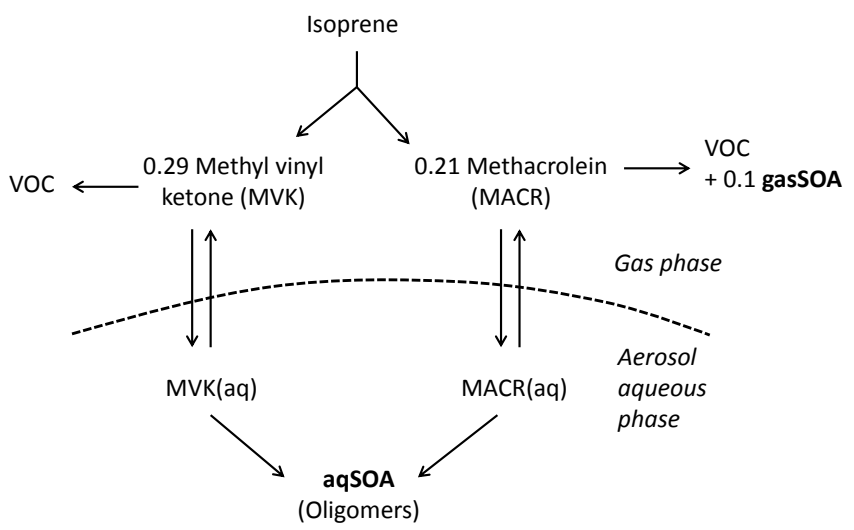

Figure 7. Schematic of SOA formation from isoprene in the atmospheric multiphase system; parameters for all processes are summarized in Tables 1-3.

\subsection{Model results}

\subsubsection{Comparison to gasSOA formation}

In the gas phase, only MACR forms SOA whereas MVK does not show any (detectable) SOA formation (Kroll et al., 2006; Surratt et al., 2006). SOA yields from isoprene are in the range of $\sim 0-5 \%$, depending on oxidant, $\mathrm{RH}$ and $\mathrm{NO}_{x}$ levels (Carlton et al., 2009), and irradiation sources employed (Carter et al., 1995; Brégonzio-Rozier et al., 2015). In order to explore the simultaneous SOA formation from isoprene in the gas and aqueous phases, we simulate the multiphase system as shown in Fig. 7. The kinetic data for gasphase reactions and uptake processes are summarized in Tables 2 and 3. For simplicity, the SOA yield from MACR is adjusted such that the overall gasSOA yield is $\sim 2 \%(=21 \%$ yield of MACR from isoprene multiplied by $10 \%$ SOA yield from MACR, resulting in a value $(2.1 \%)$ that is in the range of observed SOA yields from isoprene). The other primary reaction products (volatile organic compounds, VOCs) are not further tracked in the model, since they do not contribute to SOA mass. AqSOA formation from MVK occurs via the mechanism displayed in Fig. 1 and Table 1; aqSOA formation from MACR is approximated by $k_{\mathrm{R} 1}$. The model is initialized with $2 \mathrm{ppb}$ isoprene and $5 \times 10^{6} \mathrm{~cm}^{-3} \mathrm{OH}$ in the gas phase, both of which are kept constant; initial values for MVK and MACR are set to zero.

Simulations are performed for model cases over $6 \mathrm{~h}$. Results are shown in Fig. 8 after 2 and $6 \mathrm{~h}$ of simulation time, respectively. GasSOA masses are not affected by different loss rates into the aqueous phase. The yield of gasSOA and aqSOA, respectively, can then be calculated as

$$
Y_{\text {gasSOA }}=\frac{\mathrm{m}(\mathrm{SOA})}{k_{\mathrm{OH}, \text { isoprene }}[\mathrm{OH}][\text { isoprene }] t\left(\frac{68 \cdot 10^{15}}{6.02 e 23}\right)},
$$

where $\mathrm{m}(\mathrm{SOA})$ denotes the predicted gasSOA or aq$\mathrm{SOA}$ mass $\left[\mathrm{ng} \mathrm{m}^{-3}\right]$, respectively, $k_{\mathrm{OH}}$, isoprene is the gas- 

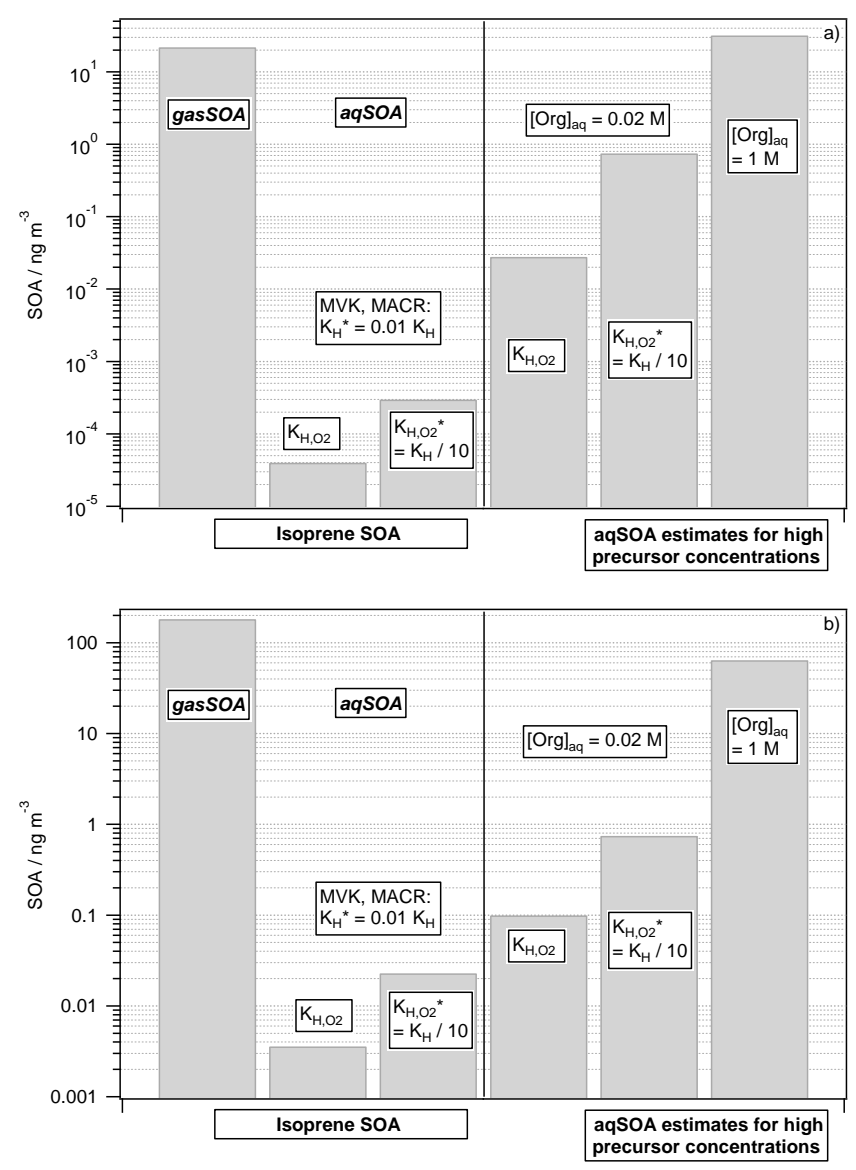

Figure 8. Comparison of aqSOA and gasSOA formation after (a) $2 \mathrm{~h}$ and (b) $6 \mathrm{~h}$. The first three bars show predicted SOA from isoprene. The last three bars show predicted aqSOA mass for assumed oligomer precursor concentrations of $0.02 \mathrm{M}$ (high and low $\mathrm{O}_{2}$ solubility) and $1 \mathrm{M}$ in aerosol water, respectively.

phase rate constant of isoprene with the $\mathrm{OH}$ radical $\left[\mathrm{cm}^{3}\right.$ molecule $\left.{ }^{-1} \mathrm{~s}^{-1}\right],[\mathrm{OH}]$ and [isoprene] are the (constant) gas-phase concentrations $\left[\mathrm{cm}^{-3}\right]$ and $t$ is the elapsed reaction time; the last term in the denominator accounts for the conversion of $\mathrm{cm}^{-3}$ to $\mathrm{ng} \mathrm{m}^{-3}$. Resulting gasSOA yields are 0.1 and $0.3 \%$ after 2 and $6 \mathrm{~h}$, respectively. AqSOA yields for the assumption of $K_{\mathrm{H}}^{*}=0.01 \cdot K_{\mathrm{H}}$ for MVK and MACR are $\sim 10^{-6} \%$ and do not exceed $10^{-4} \%$, even if one assumes $K_{\mathrm{H}}^{*}=K_{\mathrm{H}} \times 100$ (results not shown in Fig. 8). The temporal evolution of the predicted SOA (oligomer) masses is different in the laboratory experiments and the multiphase model since in the former oligomer formation rates are very high in the beginning but slow down when MVK is consumed. In the latter, the constant isoprene and oxidant concentrations in the gas phase provide an infinite supply of oligomer precursors (MVK, MACR), $\mathrm{O}_{2}$ and $\mathrm{OH}$ and therefore their ratios do not change over the simulation time.

Based on several bulk aqueous laboratory experiments (Part I), aqSOA yields of $\sim 60 \%$ have been reported for oligomerization from MVK. The multiphase model simulations as performed here show that such values should be discussed with caution in the context of atmospheric implications. Only if simultaneous gas-phase losses and uptake rates into the aqueous phase are taken into account, a solid comparison of aqSOA and gasSOA yields is feasible. Our simulations show that - even if $100 \%$ of dissolved aqSOA precursors (MVK, MACR) were converted into oligomers the overall aqSOA yield in the multiphase system might be significantly smaller $(\ll 1 \%)$.

\subsubsection{Base case: $K_{\mathrm{H}}^{*}=0.01 \cdot K_{\mathrm{H}}$}

As discussed in Sect. 3.2.2, the solubility of MVK and MACR might be reduced in aerosol water by a factor up to $\leq 100$ as compared to their solubility in pure water. Under those conditions, the resulting aqueous concentrations of MACR and MVK using the multiphase scheme in Fig. 7 are much smaller (less than micromolar) than the lowest ones $(0.2 \mathrm{mM})$ as used in the laboratory experiments discussed in Sect. 2. As can be seen in Fig. 4, the amount of oligomers is not proportionally related to the initial concentration, but it is lower by several orders of magnitude than that predicted for a 10 times higher initial MVK concentration. Note that an important difference between the multiphase simulations and the simulations mimicking the laboratory experiments in Sect. 2 is the temporal differences in the absolute MVK concentrations and concentration ratios (e.g., $[\mathrm{MVK}] /[\mathrm{OH}]_{\mathrm{aq}}$ ). While in the laboratory experiments MVK is completely consumed within 30-100 min (Fig. 2), in the atmospheric multiphase system the assumption of a constant supply seems reasonable (over relatively short timescales as simulated here) since constant isoprene emissions will provide always sufficient MVK and MACR. These differences cause a different temporal evolution of predicted oligomer masses. The results in Fig. 8 show that for the reduced solubility of MVK and MACR as it likely exists in aerosol water, the contribution of oligomers to total predicted SOA is negligible $\left(\ll 1 \mathrm{ng} \mathrm{m}^{-3}\right.$ after $6 \mathrm{~h}$ ). While not shown, it can be expected that even partitioning of MVK and MACR according to their Henry's law constants $\left(K_{\mathrm{H}}\right)$ or even for reasonable ranges of $K_{\mathrm{H}}^{*}>K_{\mathrm{H}}$ might not be sufficient to initiate efficient oligomer formation in the aqueous phase.

\subsubsection{Total initial oligomer precursor concentration}

As suggested by Eq. (5) and the fact that not only MVK and MACR but also structurally similar compounds might undergo oligomerization, we performed some sensitivity studies with different initial potential oligomer precursor concentrations. If a few $\mathrm{ng} \mathrm{m}^{-3}$ of these precursors, resulting in a total aqueous concentration of $\sim 20 \mathrm{mM}$, are dissolved in aerosol water, the predicted oligomer mass is still $<1 \%$ of predicted gasSOA mass at all times (Fig. 8). Only if a substantial fraction of all dissolved water-soluble organic carbon 
Table 2. Uptake parameters and initial conditions for box model multiphase simulations.

\begin{tabular}{|c|c|}
\hline \multicolumn{2}{|l|}{ Uptake parameters } \\
\hline Mass accommodation coefficient for MVK, MACR, $\mathrm{H}_{2} \mathrm{O}_{2}, \mathrm{OH}$ & $\alpha=1$ \\
\hline Gas-phase diffusion coefficient for MVK, MACR, $\mathrm{H}_{2} \mathrm{O}_{2}, \mathrm{OH}$ & $D_{\mathrm{g}}=2 \times 10^{-5} \mathrm{~cm}^{2} \mathrm{~s}^{-1}$ \\
\hline$K_{\mathrm{H}}^{*}(\mathrm{MVK})=K_{\mathrm{H}}(\mathrm{MVK}) \cdot 0.01^{\mathrm{a}}$ & $0.41 \mathrm{M} \mathrm{atm}^{-1}$ \\
\hline$K_{\mathrm{H}}^{*}(\mathrm{MACR})=K_{\mathrm{H}}(\mathrm{MACR}) \cdot 0.01^{\mathrm{a}}$ & $-0.065 \mathrm{M} \mathrm{atm}^{-1}$ \\
\hline$K_{\mathrm{H}}\left(\mathrm{H}_{2} \mathrm{O}_{2}\right)^{\mathrm{b}}$ & $10^{5} \mathrm{M} \mathrm{atm}^{-1}$ \\
\hline$K_{\mathrm{H}}(\mathrm{OH})^{\mathrm{c}}$ & $30 \mathrm{M} \mathrm{atm}^{-1}$ \\
\hline$K_{\mathrm{H}}\left(\mathrm{O}_{2}\right)^{\mathrm{d}}$ & $0.0013 \mathrm{M} \mathrm{atm}^{-1}$ \\
\hline \multicolumn{2}{|c|}{ Constant gas-phase mixing ratios or concentrations } \\
\hline Isoprene & $2 \mathrm{ppb}$ \\
\hline $\mathrm{H}_{2} \mathrm{O}_{2}$ & $1 \mathrm{ppb}$ \\
\hline $\mathrm{O}_{2}$ & $0.21 \mathrm{~atm}$ \\
\hline $\mathrm{OH}$ & $5 \times 10^{6} \mathrm{~cm}^{-3}$ \\
\hline \multicolumn{2}{|l|}{ Aerosol parameter } \\
\hline Particle diameter & $D_{\text {wet }}=200 \mathrm{~nm}$ \\
\hline Particle concentration & $N_{\mathrm{a}}=5000 \mathrm{~cm}^{-3}$ \\
\hline Total aerosol liquid water content & $\sim 20 \mu \mathrm{g} \mathrm{m}^{-3}$ \\
\hline
\end{tabular}

Table 3. Kinetic parameters for gas-phase reactions for the multiphase simulations to compare aqSOA and gasSOA formation from isoprene (Fig. 7).

\begin{tabular}{lll}
\hline & $\left.\begin{array}{l}k \\
\left(\mathrm{~cm}^{3} \text { molecule }\right.\end{array} \mathrm{s}^{-1}\right)$ & Reference \\
\hline Gas-phase reactions & & \\
\hline $\begin{array}{l}\text { Isoprene }+\mathrm{OH} \rightarrow 0.29 \mathrm{MVK} \\
+0.21 \mathrm{MACR}\end{array}$ & $1 \times 10^{-10}$ & Atkinson (1986) \\
$\mathrm{MVK}+\mathrm{OH} \rightarrow$ VOC & $1.85 \times 10^{-11}$ & Atkinson (1986) \\
$\mathrm{MACR}+\mathrm{OH} \rightarrow$ VOC & & \\
$+0.1 \mathrm{SOA}$ & $3.07 \times 10^{-11}$ & Atkinson (1986) \\
\hline
\end{tabular}

acts as a oligomer precursor $\left([\mathrm{Org}]_{\mathrm{aq}}=1 \mathrm{M}, \sim 150 \mathrm{ng} \mathrm{m}^{-3}\right.$ according to Eq. 5), then oligomers might substantially add to the total SOA mass. This estimate should likely be considered an upper limit. To date, only a small fraction of the total organic carbon fraction of aerosols can be usually identified on a molecular level (Herckes et al., 2013); therefore, an exact estimate of the fraction of oligomer precursors in organic aerosols cannot be given. If oligomer precursors comprise aerosol mass as implied in this estimate, their conversion to oligomers does not lead to additional SOA mass (unless heteroatoms such as oxygen are added during oligomer formation). Only if oligomer precursors are taken up from the gas phase, SOA mass addition occurs. The predicted MVK and MACR aqueous-phase concentrations are at most on the order of a micromolar (even for $K_{\mathrm{H}}^{*}=100 \cdot K_{\mathrm{H}}$ ) or correspondingly less for the assumption of lower $K_{\mathrm{H}}^{*}$ values. Oligomer precursor concentrations in the gas phase would need to be on the order of several hundreds of ppb even for very soluble precursors $\left(K_{\mathrm{H}}^{*} \sim 10^{5} \mathrm{M} \mathrm{atm}^{-1}\right.$, and accordingly higher for less soluble compounds) in order to result in millimolar or molar equilibrium concentrations in the aqueous phase.

Unlike in laboratory experiments, atmospheric aqueous aerosol particles can be considered saturated with oxygen $(\sim 270 \mu \mathrm{M})$ due to their large surface-volume ratio. In all our model sensitivity studies with the multiphase model, the oxygen concentration reached saturation level after a few seconds. Even this initial period seems to be an artifact and likely does not occur in the atmosphere where particles are continuously exposed to ambient air. Therefore, in the atmosphere, oligomerization occurs on longer timescales than in the laboratory where oxygen might be consumed over relatively short timescales (Fig. S2). Under atmospheric conditions, radical oligomerization $\left(k_{\text {olig }}\right)$ competes with the fast $\mathrm{O}_{2}$ addition on primary initiating and propagating radicals. The latter yields peroxyl radicals $\left(\mathrm{RO}_{2}^{\circ}\right)$, which are moderately reactive and can terminate propagation or may even initiate slow reactions of polymerization (Odian, 2004; Ligon et al., 2014).

\subsubsection{Oxygen solubility}

Similar to most organics, oxygen exhibits a salting-out effect; that is, $K_{\mathrm{H}}^{*}\left(\mathrm{O}_{2}\right) / K_{\mathrm{H}}\left(\mathrm{O}_{2}\right)$ is positive (Eq. 5). Depending on the salt and ionic strength, the solubility of oxygen in aerosol water might be reduced by up to an order of magnitude (Battino et al., 1983; Lang, 1996). While under such conditions 
oxygen still reaches its equilibrium concentration, the molar ratio of oligomer precursors (if assumed to be present at $\sim 20 \mathrm{mM}$ ) to dissolved oxygen approaches a value, above which efficient oligomerization in the atmosphere has been predicted ([oligomer precursors $] /\left[\mathrm{O}_{2}\right]>50$ ) (Renard et al., 2013); it is much lower if only MVK and MACR concentrations are considered.

Under such conditions, oligomer formation in aerosol water might substantially increase as compared to higher dissolved oxygen concentrations (Fig. 8). While a moderate enhancement is seen for the case for which the reduced solubility of MVK and MACR are assumed (second vs. third bars in Fig. 8), the enhancement might be much higher (fourth vs. fifth bars in Fig. 8) if a higher oligomer precursor concentration is present and therefore the ratio of [oligomer precursor $] /\left[\mathrm{O}_{2}(\mathrm{aq})\right]$ of $\sim 50$ is exceeded as observed by Renard et al. (2013). It should be noted that the concentration of dissolved oxygen in atmospheric waters has not been measured to date yet. The strong decrease in oxygen solubility, as we imply here, might only occur in very concentrated aerosol water. Under such conditions, chemical reactions might also be affected by ionic strength effects and therefore rate constants as listed in Table 1 might differ. However, it seems obvious that also other combinations of $[\mathrm{Org}]_{\mathrm{aq}}$ and $K_{\mathrm{H}}^{*}\left(\mathrm{O}_{2}\right)$ might lead to similar results as shown in the last bars in Fig. 8. Therefore, we conclude that in the presence of high concentrations of potential oligomer precursors in aerosol water, in addition to identified compounds such as MVK and MACR, conditions might be prone to efficient oligomer formation by radical processes. These oligomers might contribute on the order of several percent to total predicted SOA mass in the atmosphere.

\section{Summary and conclusions}

We have derived a comprehensive chemical mechanism of the oligomerization of methyl vinyl ketone (MVK) in the aqueous phase, based on bulk aqueous-phase laboratory studies that are described in previous work (Renard et al., 2013, 2015, Part I). Using this mechanism, model studies mimic the observed decay of MVK for a wide range of initial concentrations $\left(0.2 \mathrm{mM} \leq[\mathrm{MVK}(\mathrm{aq})]_{0} \leq 20 \mathrm{mM}\right)$. The oligomerization rates for high and low aqueous-phase concentrations of oxygen, respectively, can be reproduced by the model. This branching of reaction pathways occurs because alkyl radicals that are formed by $\mathrm{OH}$ oxidation of MVK can react either with oxygen forming peroxy radicals or with another MVK molecule, which leads to oligomers. Sensitivity studies of individual rate constants show that the derived mechanism is robust over a wide range of experimental conditions, and the set of rate constants is consistent with literature values for similar compounds.

The chemical mechanism is implemented into a multiphase box model that is initialized with isoprene ( $2 \mathrm{ppb})$ and $\mathrm{OH}$ in the gas phase. MVK and methacrolein (MACR) represent the main oxidation products of isoprene in the atmosphere. Even small SOA yields from isoprene oxidation products in the gas phase have been considered to contribute substantially to the total global SOA burden due to the high emission rate of isoprene. In an exploratory study, we compared the potential additional contributions of MVK and MACR oligomerization in the aerosol aqueous phase to the total predicted SOA mass. Our model results show that oligomerization by MVK and MACR in aerosol particles is likely not efficient under atmospheric conditions, in particular since the solubility of MVK and MACR is reduced due to salting-out effects. MVK and MACR can be considered as two precursors of likely many more structurally similar compounds in the atmosphere. If a small fraction of organic aerosol carbon $\left(\sim 100 \mathrm{ng} \mathrm{m}^{-3}\right)$ is comprised of such compounds, resulting in aqueous-phase concentrations of $\sim 1 \mathrm{M}$, their oligomerization might contribute a few percent to total predicted SOA mass.

While in laboratory experiments solutions often are not saturated with oxygen, such conditions are likely not met in the atmosphere due to the large surface-to-volume ratio of ambient aerosol particles (and cloud droplets) that allows an efficient replenishment of consumed oxygen. However, while organics might exhibit salting-in or salting-out effects in salt solutions, oxygen is always salted out; that is, it is less soluble in aerosol water than in pure water. If the oxygen solubility is reduced by 1 order of magnitude (as observed in concentrated salt solutions), a few $\mathrm{ng} \mathrm{m}^{-3}$ of unsaturated organic carbon is sufficient to act as efficient oligomer precursors. In summary, our study suggests that only if the total of unsaturated organics in aerosol water were present at concentrations of $\sim 1 \mathrm{M}$ (corresponding to several hundreds of ppb of highly soluble precursors in the gas phase), radical oligomerization might contribute considerably to total aqSOA and SOA in the atmosphere.

\section{The Supplement related to this article is available online at doi:10.5194/acp-15-9109-2015-supplement.}

Acknowledgements. All authors are thankful to Veronica Vaida and Barney Ellison for valuable discussions on the chemical mechanism. B. Ervens acknowledges support from NOAA's climate goal. A. Monod acknowledges support from CIRES (visiting fellowship) and the National Research Agency ANR (project CUMULUS ANR-2010-BLAN-617-01). P. Renard acknowledges AXA insurances for funding this research.

Edited by: S. A. Nizkorodov 


\section{References}

Alfassi, Z. B.: The chemistry of free radicals: Peroxyl radicals, 1st ed., Wiley, West Sussex, England, 546 pp., 1997.

Altieri, K., Carlton, A. G., Lim, H., Turpin, B. J., and Seitzinger, S. P.: Evidence for oligomer formation in clouds: Reaction of isoprene oxidation products, Environ. Sci. Technol., 40, 49564960, 2006.

Altieri, K. E., Turpin, B. J., and Seitzinger, S. P.: Oligomers, organosulfates, and nitrooxy organosulfates in rainwater identified by ultra-high resolution electrospray ionization FTICR mass spectrometry, Atmos. Chem. Phys., 9, 2533-2542, doi:10.5194/acp-9-2533-2009, 2009.

Arakaki, T., Anastasio, C., Kuroki, Y., Nakajima, H., Okada, K., Kotani, Y., Handa, D., Azechi, S., Kimura, T., Tsuhako, A., and Miyagi, Y.: A general scavenging rate constant for reaction of hydroxyl radical with organic carbon in atmospheric waters, Environ. Sci. Technol., 47, 8196-8203, doi:10.1021/es401927b, 2013.

Atkinson, R.: Kinetics and mechanisms of the gas-phase reactions of the hydroxyl radical with organic compounds under atmospheric conditions, Chem. Rev., 86, 1, 69-201, doi:10.1021/cr00071a004, 1986.

Baboukas, E. D., Kanakidou, M., and Mihalopoulos, N.: Carboxylic acids in gas and particulate phase above the Atlantic Ocean, J. Geophys. Res.-Atmos., 105, 14459-14471, 2000.

Battino, R., Rettich, T. R., and Tominaga, T.: The solubility of oxygen and ozone in liquids, J. Phys. Chem. Ref. Data, 12, 163-178, 1983.

Bielski, B. H. J., Cabell, D. E., Arudi, R. L., and Ross, A. B.: Reactivity of $\mathrm{HO}_{2} / \mathrm{O}_{2}^{-}$radicals in aqueous solution, J. Phys. Chem. Ref. Data, 14, 1041-1100, 1985.

Blanksby, S. J. and Ellison, G. B.: Bond dissociation energies of organic molecules, Acc. Chem. Res., 36, 255-263, doi:10.1021/ar020230d, 2003.

Brégonzio-Rozier, L., Siekmann, F., Giorio, C., Pangui, E., Morales, S. B., Temime-Roussel, B., Gratien, A., Michoud, V., Ravier, S., Cazaunau, M., Tapparo, A., Monod, A., and Doussin, J.-F.: Gaseous products and secondary organic aerosol formation during long term oxidation of isoprene and methacrolein, Atmos. Chem. Phys., 15, 2953-2968, doi:10.5194/acp-15-29532015, 2015.

Carlton, A. G., Wiedinmyer, C., and Kroll, J. H.: A review of Secondary Organic Aerosol (SOA) formation from isoprene, Atmos. Chem. Phys., 9, 4987-5005, doi:10.5194/acp-9-4987-2009, 2009.

Carter, W. P. L., Luo, D., Malkina, I. L., and Pierce, J. A.: Environmental chamber studies of atmospheric reactivities of volatile organic compounds. Effects of varying chamber and light source, California Air Resources Board Contract A032-0692, and South Coast Air Quality Management District Coordinating Research Council, Inc., Project M-9, 1995.

Chin, M. and Wine, P. H.: A temperature-dependent competitive kinetics study of the aqueous-phase reactions of $\mathrm{OH}$ radicals with formate, formic acid, acetate, acetic acid and hydrated formaldehyde, in: Aquatic and Surface Photochemistry, edited by: Helz, G. R., Zepp, R. G., and Crosby, D. G., Lewis Publishers, Boca Raton, 85-96, 1994.

Christensen, H., Sehested, K., and Corfitzen, H.: Reactions of hydroxyl radicals with hydrogen peroxide at ambient and elevated temperatures, J. Phys. Chem., 86, 1588-1590, doi:10.1021/j100206a023, 1982.

Denkenberger, K. A., Moffet, R. C., Holecek, J. C., Robetier, T. P., and Prather, K. A.: Real-time, single-particle measurements of oligomers in aged ambient aerosol particles, Environ. Sci. Technol., 41, 5439-5446, 2007.

Donahue, N. M., Robinson, A. L., Stanier, C. O., and Pandis, S. N.: Coupled partitioning, dilution and chemical aging of semivolatile organics, Environ. Sci. Technol., 40, 2635-2643, 2006.

Donahue, N. M., Epstein, S. A., Pandis, S. N., and Robinson, A. L.: A two-dimensional volatility basis set: 1. organic-aerosol mixing thermodynamics, Atmos. Chem. Phys., 11, 3303-3318, doi:10.5194/acp-11-3303-2011, 2011.

Donaldson, D. J. and Valsaraj, K. T.: Adsorption and reaction of trace gas-phase organic compounds on atmospheric water film surfaces: A critical review, Environ. Sci. Technol., 44, 865-873, doi:10.1021/es902720s, 2010.

Doussin, J.-F. and Monod, A.: Structure-activity relationship for the estimation of $\mathrm{OH}$-oxidation rate constants of carbonyl compounds in the aqueous phase, Atmos. Chem. Phys., 13, 1162511641, doi:10.5194/acp-13-11625-2013, 2013.

El Haddad, I., Yao Liu, Nieto-Gligorovski, L., Michaud, V., Temime-Roussel, B., Quivet, E., Marchand, N., Sellegri, K., and Monod, A.: In-cloud processes of methacrolein under simulated conditions - Part 2: Formation of secondary organic aerosol, Atmos. Chem. Phys., 9, 5107-5117, doi:10.5194/acp-9-5107-2009, 2009.

Elliot, A. J. and Buxton, G. V.: Temperature dependence of the reactions $\mathrm{OH}+\mathrm{O}_{2}^{-}$and $\mathrm{OH}+\mathrm{HO}_{2}$ in water up to $200^{\circ} \mathrm{C}$, J. Chem. Soc. Faraday Trans., 88, 2465-2470, 1992.

Epstein, S. A., Tapavicza, E., Furche, F., and Nizkorodov, S. A.: Direct photolysis of carbonyl compounds dissolved in cloud and fog droplets, Atmos. Chem. Phys., 13, 9461-9477, doi:10.5194/acp-13-9461-2013, 2013.

Ervens, B.: Modeling the Processing of Aerosol and Trace Gases in Clouds and Fogs, Chemical Reviews, 115, 4157-4198, doi:10.1021/cr5005887, 2015.

Ervens, B., Gligorovski, S., and Herrmann, H.: Temperature dependent rate constants for hydroxyl radical reactions with organic compounds in aqueous solution, Phys. Chem. Chem. Phys., 5, 1811-1824, 2003.

Ervens, B., Turpin, B. J., and Weber, R. J.: Secondary organic aerosol formation in cloud droplets and aqueous particles (aqSOA): a review of laboratory, field and model studies, Atmos. Chem. Phys., 11, 11069-11102, doi:10.5194/acp-1111069-2011, 2011.

Galloway, M. M., Huisman, A. J., Yee, L. D., Chan, A. W. H., Loza, C. L., Seinfeld, J. H., and Keutsch, F. N.: Yields of oxidized volatile organic compounds during the $\mathrm{OH}$ radical initiated oxidation of isoprene, methyl vinyl ketone, and methacrolein under high- $\mathrm{NO}_{\mathrm{x}}$ conditions, Atmos. Chem. Phys., 11, 10779-10790, doi:10.5194/acp-11-10779-2011, 2011.

Gilbert, B. C., Holmes, R. G. G., Laue, H. A. H., and Norman, R. O. C.: Electron spin resonance studies. Part L. Reactions of alkoxyl radicals generated from alkyl hydroperoxides and titanium(III) ion in aqueous solution, J. Chem. Soc., Perk. T. 2, 1047-1052, doi:10.1039/p29760001047, 1976.

Gilbert, B. C., Smith, J. R. L., Milne, E. C., Whitwood, A. C., and Taylor, P.: Kinetic and structural EPR studies of radical polymer- 
ization. Monomer, dimer, trimer and mid-chain radicals formed via the initiation of polymerization of acrylic acid and related compounds with electrophilic radicals $\left({ }^{\bullet} \mathrm{OH}, \mathrm{SO}_{4}^{-\bullet}\right.$ and $\left.\mathrm{Cl}_{2}^{-\bullet}\right)$, J. Chem. Soc., Perk. T. 2, 1759-1769, doi:10.1039/p29940001759, 1994.

Guzman, M. I., Colussi, A. J., and Hoffmann, M. R.: Photoinduced oligomerization of aqueous pyruvic acid, J. Phys. Chem. A, 110, 3619-3626, 2006.

Hanson, D. R., Burkholder, J. B., Howard, C. J., and Ravishankara, A. R.: Measurement of hydroxyl and hydroperoxy radical uptake coefficients on water and sulfuric acid surfaces, J. Phys. Chem., 96, 4979-4985, doi:10.1021/j100191a046, 1992.

Healy, R. M., Wenger, J. C., Metzger, A., Duplissy, J., Kalberer, M., and Dommen, J.: Gas/particle partitioning of carbonyls in the photooxidation of isoprene and 1,3,5-trimethylbenzene, Atmos. Chem. Phys., 8, 3215-3230, doi:10.5194/acp-8-3215-2008, 2008.

Herckes, P., Valsaraj, K. T., and Collett Jr, J. L.: A review of observations of organic matter in fogs and clouds: Origin, processing and fate, Atmos. Res., 132-133, 434-449, doi:10.1016/j.atmosres.2013.06.005, 2013.

Herrmann, H., Hoffmann, D., Schaefer, T., Bräuer, P., and Tilgner, A.: Tropospheric Aqueous-Phase Free-Radical Chemistry: Radical Sources, Spectra, Reaction Kinetics and Prediction Tools, Chem. Phys. Chem, 11, 3796-3822, doi:10.1002/cphc.201000533, 2010.

Iraci, L. T., Baker, B. M., Tyndall, G. S., and Orlando, J. J.: Measurements of the Henry's law coefficients of 2-methyl-3-buten-2ol, methacrolein, and methylvinyl ketone, J. Atmos. Chem., 33, 321-330, 1999.

Kalberer, M., D. Paulsen, M. Sax, M. Steinbacher, J. Dommen, A. S. H. Prevot, R. Fisseha, E. Weingartner, V. Frankevich, R. Zenobi, and Baltensperger, U.: Identification of polymers as major components of atmospheric organic aerosols, Science, 303, 1659-1662, 2004.

Kampf, C. J., Waxman, E. M., Slowik, J. G., Dommen, J., Pfaffenberger, L., Praplan, A. P., Prévôt, A. S. H., Baltensperger, U., Hoffmann, T., and Volkamer, R.: Effective Henry's Law Partitioning and the Salting Constant of Glyoxal in Aerosols Containing Sulfate, Environ. Sci. Technol., 47, 4236-4244, doi:10.1021/es400083d, 2013.

Kanakidou, M., Seinfeld, J. H., Pandis, S. N., Barnes, I., Dentener, F. J., Facchini, M. C., Van Dingenen, R., Ervens, B., Nenes, A., Nielsen, C. J., Swietlicki, E., Putaud, J. P., Balkanski, Y., Fuzzi, S., Horth, J., Moortgat, G. K., Winterhalter, R., Myhre, C. E. L., Tsigaridis, K., Vignati, E., Stephanou, E. G., and Wilson, J.: Organic aerosol and global climate modelling: a review, Atmos. Chem. Phys., 5, 1053-1123, doi:10.5194/acp-5-1053-2005, 2005.

Kawamura, K., Okuzawa, K., Aggarwal, S. G., Irie, H., Kanaya, Y., and Wang, Z.: Determination of gaseous and particulate carbonyls (glycolaldehyde, hydroxyacetone, glyoxal, methylglyoxal, nonanal and decanal) in the atmosphere at Mt. Tai, Atmos. Chem. Phys., 13, 5369-5380, doi:10.5194/acp-13-53692013, 2013.

Kroll, J. H., Ng, N. L., Murphy, S. M., Flagan, R. C., and Seinfeld, J. H.: Secondary organic aerosol formation from isoprene photooxidation under high $\mathrm{NO}_{x}$ conditions, Geophys. Res. Lett., 32, L18808, doi:10.1029/2005GL023637, 2005.
Kroll, J. H., Ng, N. L., Murphy, S. M., Flagan, R. C., and Seinfeld, J. H.: Secondary organic aerosol formation from isoprene photooxidation, Environ. Sci. Technol., 40, 1869-1877, 2006.

Kuwata, M., Liu, Y., McKinney, K., and Martin, S. T.: Physical state and acidity of inorganic sulfate can regulate the production of secondary organic material from isoprene photooxidation products, Phys. Chem. Chem. Phys., 17, 5670-5678, doi:10.1039/c4cp04942j, 2015.

Kwon, B. G. and Kwon, J.-H.: Measurement of the hydroxyl radical formation from $\mathrm{H}_{2} \mathrm{O}_{2}, \mathrm{NO}_{3}^{-}$, and $\mathrm{Fe}(\mathrm{III})$ using a continuous flow injection analysis, J. Ind. Eng. Chem. , 16, 193-199, doi:10.1016/j.jiec.2009.10.007, 2010.

Lang, W.: Setchenov coefficients for oxygen in aqueous solutions of various organic compounds, Fluid Phase Equilibr., 114, 123133, doi:10.1016/0378-3812(95)02823-4, 1996.

Ligon, S. C., Husár, B., Wutzel, H., Holman, R., and Liska, R.: Strategies to Reduce Oxygen Inhibition in Photoinduced Polymerization, Chem. Rev., 114, 557-589, doi:10.1021/cr3005197, 2014.

Lim, Y. B., Tan, Y., Perri, M. J., Seitzinger, S. P., and Turpin, B. J.: Aqueous chemistry and its role in secondary organic aerosol (SOA) formation, Atmos. Chem. Phys., 10, 1052110539, doi:10.5194/acp-10-10521-2010, 2010.

Lim, Y. B., Tan, Y., and Turpin, B. J.: Chemical insights, explicit chemistry, and yields of secondary organic aerosol from $\mathrm{OH}$ radical oxidation of methylglyoxal and glyoxal in the aqueous phase, Atmos. Chem. Phys., 13, 8651-8667, doi:10.5194/acp-13-86512013, 2013.

Lind, J. A. and Kok, G. L.: Henry's law Determinations for aqueous solutions of hydrogen peroxide, methylhydroperoxide and peroxyacetic acid, J. Geophys. Res., 91, 7889-7895, 1986.

Liu, Y., El Haddad, I., Scarfogliero, M., Nieto-Gligorovski, L., Temime-Roussel, B., Quivet, E., Marchand, N., Picquet-Varrault, B., and Monod, A.: In-cloud processes of methacrolein under simulated conditions - Part 1: Aqueous phase photooxidation, Atmos. Chem. Phys., 9, 5093-5105, doi:10.5194/acp-9-50932009, 2009.

Liu, Y., Monod, A., Tritscher, T., Praplan, A. P., DeCarlo, P. F., Temime-Roussel, B., Quivet, E., Marchand, N., Dommen, J., and Baltensperger, U.: Aqueous phase processing of secondary organic aerosol from isoprene photooxidation, Atmos. Chem. Phys., 12, 5879-5895, doi:10.5194/acp-12-5879-2012, 2012.

Long, T. E., McGrath, J. E., and Richard, S.: Polymers, Synthesis, pp. 751-774, in: Encyclopedia of physical science and technology, Polymers, 3rd ed., edited by: Meyers, R. A., Academic Press, New York, 15453 pp., 2001.

Mackay, D. and Shiu, W. Y.: A critical review of Henry's law constants for chemicals of environmental interest, J. Phys. Chem. Ref. Data 10, 1175-1199, 1981.

Matsunaga, S. N., Kato, S., Yoshino, A., Greenberg, J. P., Kajii, Y., and Guenther, A. B.: Gas-aerosol partitioning of semi volatile carbonyls in polluted atmosphere in Hachioji, Tokyo, Geophys. Res. Lett., 32, L11805, doi:10.1029/2004g1021893, 2005.

Mazzoleni, L. R., Ehrmann, B. M., Shen, X., Marshall, A. G., and Collett, J. L.: Water-soluble atmospheric organic matter in fog: Exact masses and chemical formula identification by ultrahigh-resolution Fourier transform ion cyclotron resonance mass Spectrometry, Environ. Sci. Technol., 44, 3690-3697, doi:10.1021/es903409k, 2010. 
Mead, R. N., Mullaugh, K. M., Brooks Avery, G., Kieber, R. J., Willey, J. D., and Podgorski, D. C.: Insights into dissolved organic matter complexity in rainwater from continental and coastal storms by ultrahigh resolution Fourier transform ion cyclotron resonance mass spectrometry, Atmos. Chem. Phys., 13, 48294838, doi:10.5194/acp-13-4829-2013, 2013.

Mead, R. N., Felix, J. D., Avery, G. B., Kieber, R. J., Willey, J. D., and Podgorski, D. C.: Characterization of CHOS compounds in rainwater from continental and coastal storms by ultrahigh resolution mass spectrometry, Atmos. Environ., 105, 162-168, doi:10.1016/j.atmosenv.2015.01.057, 2015.

Mendez, M., Ciuraru, R., Gosselin, S., Batut, S., Visez, N., and Petitprez, D.: Reactivity of chlorine radical with submicron palmitic acid particles: kinetic measurements and product identification, Atmos. Chem. Phys., 13, 11661-11673, doi:10.5194/acp-13-11661-2013, 2013.

Michaud, V., El Haddad, I., Yao Liu, Sellegri, K., Laj, P., Villani, P., Picard, D., Marchand, N., and Monod, A.: In-cloud processes of methacrolein under simulated conditions - Part 3: Hygroscopic and volatility properties of the formed secondary organic aerosol, Atmos. Chem. Phys., 9, 5119-5130, doi:10.5194/acp-95119-2009, 2009.

Monod, A., Chebbi, A., Durand-Jolibois, R., and Carlier, P.: Oxidation of methanol by hydroxyl radicals in aqueous solution under simulated cloud droplet conditions, Atmos. Environ., 34, 52835294, 2000.

Monod, A., Poulain, L., Grubert, S., Voisin, D., and Wortham, H.: Kinetics of $\mathrm{OH}-$ initiated oxidation of oxygenated organic compounds in the aqueous phase: new rate constants, structureactivity relationships and atmospheric implications, Atmos. Environ., 39, 7667-7688, 2005.

Monod, A., Chevallier, E., Jolibos, R. D., Doussin, J. F., PicquetVarrault, B., and Carlier, P.: Photooxidation of methylhydroperoxide and ethylhydroperoxide in the aqueous phase under simulated cloud droplet conditions, Atmos. Environ., 41, 2412-2426, 2007.

NDRL/NIST: Solution Kinetics Database on the Web, http:// kinetics.nist.gov/solution/ (last access: 18 May 2015), 2002.

Neta, P., Huie, R. E., and Ross, A. B.: Rate constants for reactions of peroxyl radicals in fluid solutions, J. Phys. Chem. Ref. Data, 19, 413-513, 1990.

Noziere, B., Voisin, D., Longfellow, C. A., Friedli, H., Henry, B. E., and Hanson, D. R.: The uptake of methyl vinyl ketone, methacrolein, and 2-methyl-3-butene-2-ol onto sulfuric acid solutions, J. Phys. Chem. A, 110, 2387-2395, 2006.

Noziere, B., Dziedzic, P., and Cordova, A.: Inorganic ammonium salts and carbonate salts are efficient catalysts for aldol condensation in atmospheric aerosols, Phys. Chem. Chem. Phys., 12, 3864-3872, 2010.

Odian, G.: Principles of Polymerization, John Wiley \& Sons Inc., Hoboken, New Jersey, 835 pp., 2004.

Odum, J. R., Hoffmann, T., Bowman, F., Collins, D., Flagan, R. C., and Seinfeld, J. H.: Gas/particle partitioning and secondary organic aerosol yields, Environ. Sci. Technol., 30, 2580-2585, 1996.

Paasivirta, J., Sinkkonen, S., Mikkelson, P., Rantio, T., and Wania, F.: Estimation of Vapor Pressures, Solubilities and Henry's Law Constants of selected persistent organic Pollutants as Functions of Temperature, Chemosphere, 39, 811-832, 1999.
Polidori, A., Turpin, B. J., Davidson, C. I., Rodenburg, L. A., and Maimone, F.: Organic PM2.5: Fractionation by polarity, FTIR Spectroscopy, and OM/OC ratio for the Pittsburgh aerosol, Aer. Sci. Tech., 42, 233-246, 2008.

Reed-Harris, A., Ervens, B., Shoemaker, R. K., Griffith, E. C., Rapf, R. J., Kroll, J., Monod, A., and Vaida, V.: Photochemical kinetics of pyruvic acid in aqueous solution, J. Phys. Chem. A, 118, 8505-8516, 2014.

Renard, P., Siekmann, F., Gandolfo, A., Socorro, J., Salque, G., Ravier, S., Quivet, E., Clément, J.-L., Traikia, M., Delort, A.M., Voisin, D., Vuitton, V., Thissen, R., and Monod, A.: Radical mechanisms of methyl vinyl ketone oligomerization through aqueous phase $\mathrm{OH}$-oxidation: on the paradoxical role of dissolved molecular oxygen, Atmos. Chem. Phys., 13, 6473-6491, doi:10.5194/acp-13-6473-2013, 2013.

Renard, P., Siekmann, F., Salque, G., Demelas, C., Coulomb, B., Vassalo, L., Ravier, S., Temime-Roussel, B., Voisin, D., and Monod, A.: Aqueous-phase oligomerization of methyl vinyl ketone through photooxidation - Part 1: Aging processes of oligomers, Atmos. Chem. Phys., 15, 21-35, doi:10.5194/acp-1521-2015, 2015.

Sander, R.: Compilation of Henry's law constants (version 4.0) for water as solvent, Atmos. Chem. Phys., 15, 4399-4981, doi:10.5194/acp-15-4399-2015, 2015.

Schaefer, T., Schindelka, J., Hoffmann, D., and Herrmann, H.: Laboratory kinetic and mechanistic studies on the $\mathrm{OH}$-initiated oxidation of acetone in aqueous solution, J. Phys. Chem. A, 116, 6317-6326, doi:10.1021/jp2120753, 2012.

Schaefer, T., van Pinxteren, D., and Herrmann, H.: Multiphase Chemistry of Glyoxal: Revised Kinetics of the Alkyl Radical Reaction with Molecular Oxygen and the Reaction of Glyoxal with $\mathrm{OH}, \mathrm{NO}_{3}$, and $\mathrm{SO}_{4}-$ in Aqueous Solution, Environ. Sci. Technol., 49, 343-350, doi:10.1021/es505860s, 2015.

Schöne, L. and Herrmann, H.: Kinetic measurements of the reactivity of hydrogen peroxide and ozone towards small atmospherically relevant aldehydes, ketones and organic acids in aqueous solutions, Atmos. Chem. Phys., 14, 4503-4514, doi:10.5194/acp-14-4503-2014, 2014.

Schöne, L., Schindelka, J., Szeremeta, E., Schaefer, T., Hoffmann, D., Rudzinski, K. J., Szmigielski, R., and Herrmann, H.: Atmospheric aqueous phase radical chemistry of the isoprene oxidation products methacrolein, methyl vinyl ketone, methacrylic acid and acrylic acid - kinetics and product studies, Phys. Chem. Chem. Phys., 16, 6257-6272, doi:10.1039/c3cp54859g, 2014.

Schuchmann, H.-P. and von Sonntag, C.: Photolysis at $185 \mathrm{~nm}$ of dimethyl ether in aqueous solution: involvement of the hydroxymethyl radical, J. Photochem., 16, 289-295,doi:10.1016/00472670(81)80051-2, 1981.

Schuchmann, H.-P. and von Sonntag, C.: Methylperoxyl Radicals: A Study of the y-Radiolysis of Methane in Oxygenated Aqueous Solutions, Z. Naturforschung, 39b, 217-221, 1984.

Schwartz, S.: Mass transport considerations pertinent to aqueous phase reactions of gases in liquid water clouds, in: Chemistry of Multiphase Atmospheric Systems, edited by: Jaeschke, W., NATO ASI Series, Springer, Berlin, 415-471, 1986.

Stefan, M. I. and Bolton, J. R.: Reinvestigation of the acetone degradation mechanism in dilute aqueous solution by the $\mathrm{UV} / \mathrm{H}_{2} \mathrm{O}_{2}$ process, Environ. Sci. Technol., 33, 870-873, 1999. 
Surratt, J. D., Murphy, S. M., Kroll, J. H., Ng, N. L., Hildebrandt, L., Sorooshian, A., Szmigielski, R., Vermeylen, R., Maenhaut, W., Claeys, M., Flagan, R. C., and Seinfeld, J. H.: Chemical composition of secondary organic aerosol formed from the photooxidation of isoprene, J. Phys. Chem. A, 110, 31, 9665-9690, doi:10.1021/jp061734m, 2006

Tolocka, M. P., Jang, M., Ginter, J. M., Cox, F. J., Kamens, R. M., and Johnston, M. J.: Formation of oligomers in secondary organic aerosol, Environ. Sci. Technol., 38, 1428-1434, 2004.

Trump, E. R. and Donahue, N. M: Oligomer formation within secondary organic aerosols: equilibrium and dynamic considerations, Atmos. Chem. Phys., 14, 3691-3701, doi:10.5194/acp-143691-2014, 2014.

von Sonntag, C. and Schuchmann, H.-P.: Peroxyl radicals in aqueous solution, in: Peroxyl Radicals, edited by: Alfassi, Z. B., Wiley, Chichester, 173-234, 1997.

Wang, C., Lei, Y. D., Endo, S., and Wania, F.: Measuring and Modeling the Salting-out Effect in Ammonium Sulfate Solutions, Environ. Sci. Technol., 48, 13238-13245, doi:10.1021/es5035602, 2014.
Zhang, H. and Ying, Q.: Secondary organic aerosol formation and source apportionment in Southeast Texas, Atmos. Environ. , 45, 3217-3227, doi:10.1016/j.atmosenv.2011.03.046, 2011.

Zhang, Q., Jimenez, J. L., Canagaratna, M. R., Allan, J. D., Coe, H., Ulbrich, I., Alfarra, M. R., Takami, A., Middlebrook, A. M., Sun, Y. L., Dzepina, K., Dunlea, E., Docherty, K., DeCarlo, P. F., Salcedo, D., Onasch, T., Jayne, J. T., Miyoshi, T., Shimono, A., Hatekayama, S., Takegawa, N., Kondo, Y., Schneider, J., Drewnick, F., Borrmann, S., Weiner, S., Demerijan, K., Williams, P., Bower, K., Bahreini, R., Cottrell, L., Griffin, R. J., Rautiainen, J., Sun, J. Y., Zhang, Y. M., and Worsnop, D. R.: Ubiquity and dominance of oxygenated species in organic aerosols in anthropogenically-influenced Northern Hemisphere midlatitudes, Geophys. Res. Lett., 34, L13801, doi:10.1029/2007GL029979, 2007.

Zhang, X., Chen, Z. M., and Zhao, Y.: Laboratory simulation for the aqueous $\mathrm{OH}$-oxidation of methyl vinyl ketone and methacrolein: significance to the in-cloud SOA production, Atmos. Chem. Phys., 10, 9551-9561, doi:10.5194/acp-10-9551-2010, 2010. 